\title{
Simulation of chemo-thermo-mechanical problems in cement-based materials with Peridynamics
}

\author{
Soheil Bazazzadeh (1) - Marco Morandini - Mirco Zaccariotto (i) \\ Ugo Galvanetto
}

Received: 12 December 2020/ Accepted: 8 May 2021/Published online: 7 June 2021

(C) The Author(s) 2021

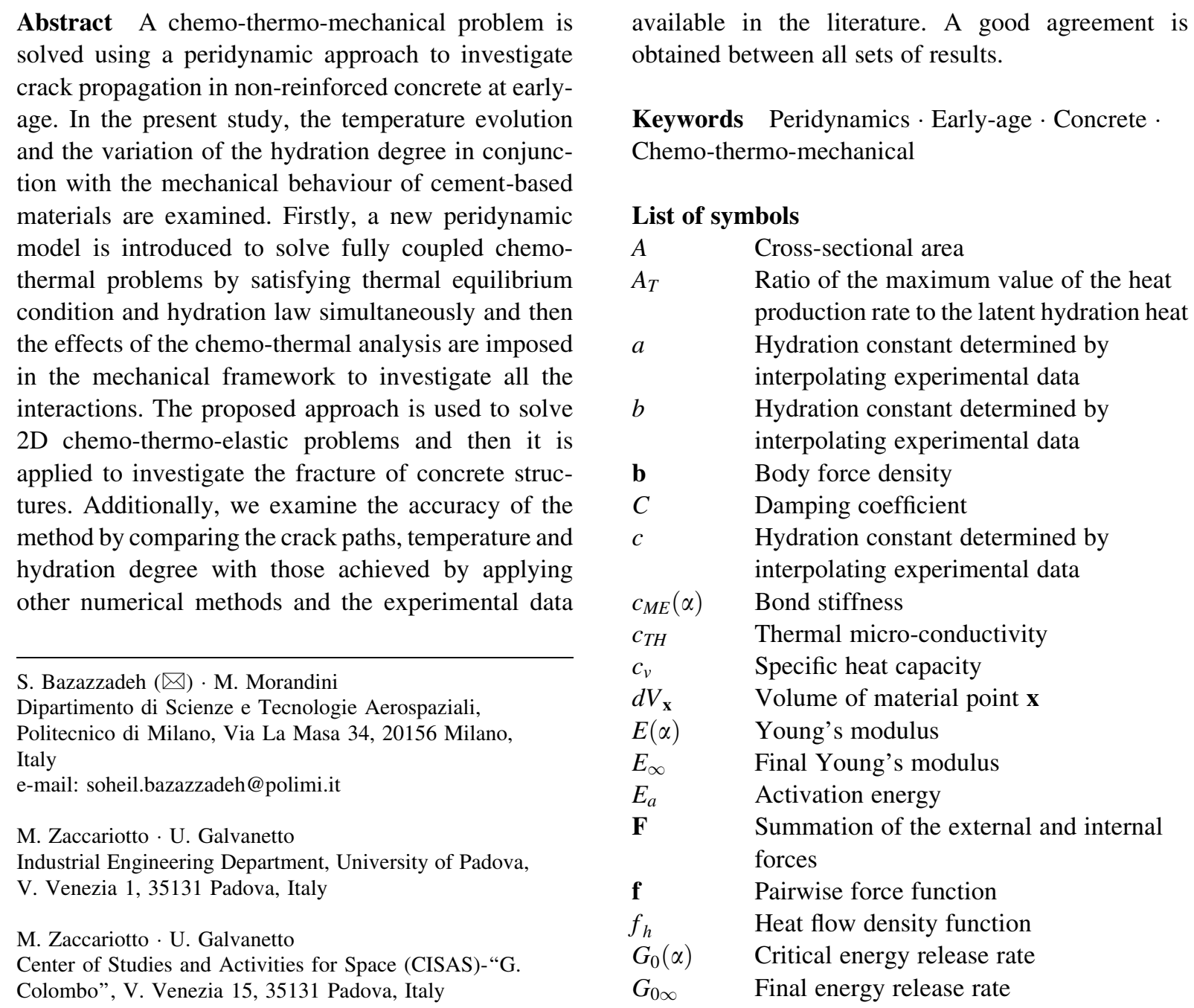




$\begin{array}{llll}H(\mathbf{x}) & \text { Neighborhood of point } \mathbf{x} & \rho & \text { Mass density } \\ h & \text { Convective heat transfer coefficient } & \tau\left(\mathbf{x}^{\prime}, \mathbf{x}, t\right) & \begin{array}{l}\text { Temperature difference between } \\ \text { interacting points }\end{array} \\ h_{s} & \text { Heat source } & & \text { Solution domain } \\ k & \text { Thermal conductivity } & \Omega & \text { Scalar influence function } \\ m & \text { Ratio between the horizon size and the } & \omega & \text { Relative position between two material } \\ & \text { grid spacing } & \xi & \text { points } \\ \dot{Q} & \text { Flowing heat rate } & & \end{array}$

$\tilde{Q} \quad$ Volumetric flowing heat rate

$Q_{\infty} \quad$ Potential heat of the hydration reaction

q Heat flux

$R \quad$ Ideal gas constant

$S \quad$ Area where the heat flux is imposed

$s \quad$ Stretch of bond

$s_{0}(\alpha) \quad$ Critical stretch

$T \quad$ Temperature

$T_{0} \quad$ Reference temperature

$T_{a}(\mathbf{x}, t) \quad$ Air temperature

$T_{s}(\mathbf{x}, t) \quad$ Body surface temperature

$\bar{t} \quad$ Thickness of the body for a 2D case

U Displacement vector

u Displacement field

$V_{f} \quad$ Volume of the boundary region

X Positions vector

$\mathbf{x}, \mathbf{x}^{\prime} \quad$ Material points

$\mathbf{y}(\mathbf{x}, t) \quad$ Current position of point $\mathbf{x}$ at time $t$

$\alpha \quad$ Hydration degree

$\alpha_{E} \quad$ Threshold hydration degree constant for the Young's modulus

$\alpha_{G_{0}} \quad$ Threshold hydration degree constant for the critical energy release rate

$\alpha_{a u} \quad$ Mechanical percolation threshold

$\beta \quad$ Volume correction function

$\beta^{\prime} \quad$ Thermal expansion coefficient

$\Delta T_{\text {avg }} \quad$ Average temperature of each bond

$\Delta \alpha_{\text {avg }} \quad$ Average hydration degree of each bond

$\Delta t \quad$ Time step

$\Delta t_{M E} \quad$ Incremental time step corresponding to mechanical analysis

$\Delta t_{C T} \quad$ Incremental time step corresponding to chemo-thermal analysis

$\Delta x \quad$ Grid size

$\delta \quad$ Horizon size

$\phi(\mathbf{x}, t) \quad$ Damage level of point $\mathbf{x}$

$\boldsymbol{\eta} \quad$ Relative displacement

$\kappa \quad$ Shrinkage material constant

$\mu(\xi, t) \quad$ History-dependent function

$v \quad$ Poison's ratio

$\Lambda \quad$ Fictitious Diagonal density

\begin{abstract}
Acronyms
PDEs Partial differential equations

BB-PD Bond-based peridynamics

FEM Finite element method
\end{abstract}

\section{Introduction}

Cement hydration and shrinkage is a phenomenon characterized by inhomogeneous stresses occurring in plain and non-reinforced concrete. Concrete is widely used in infrastructures such as airfields, slabs and dams [1]. A significant disadvantage of concrete is its sensitivity with respect to the early-age cracking in aforementioned structures. Hence, a basic understanding of material performance due to early-age cracking is required in the design of concrete structures [1,2]. Due to the fast change of mechanical properties such as strength of the material $[3,4]$, prediction of the behaviour of concrete is still not a trivial task. In fact, during cement hydration process, the mechanical properties of the material strongly tie in with the physical and chemical processes. In this multi-physics problem all the thermal, mechanical and chemical effects should be considered [2]. Therefore, it is still a challenging issue to precisely predict the early-age behaviour of the cement based material, especially when discontinuities such as cracks occur. Numerous numerical and experimental studies have been so far performed to analyse the mechanical behaviour of early-age non-reinforced concrete. Among the experimental studies, Kolver et al. [5] and Qstergaard et al. [6] have investigated the tensile creep of concrete at early-age. In [7], a restrained shrinkage test has been developed to characterize the early-age mechanical behaviour. Moreover, the type of cement and effects of curing temperature on the shrinkage properties have been investigated in [8]. The emergence of cracks due to autogenous shrinkage in high performance and slag cement concrete have been investigated in [9, 10], respectively. Later, early age hygro-thermo-chemo- 
mechanical reactions have been studied in [11-19]. For early age behaviour of concrete the numerical studies by [20-23] should be mentioned here. Moreover, in [24-26], cracking risk analysis is performed by using smeared-crack and crack band models, respectively. Other numerical approaches such as microplane approach in [27] or lattice approach in [28] are used to investigate the early-age concrete behaviour. Soon afterwards, Neguyen et al. [1, 29] have proposed a phase field model to investigate complex fracture induced by early-age shrinkage and hydration heat in cement based materials. Other numerical methods in this field can be traced in [30-32].

However, due to the complexity of the hydration process, available computational approaches cannot precisely describe how complex crack patterns nucleate and evolve in concrete structures. The majority of the proposed computational techniques are yet able to merely predict the crack propagation induced by cement hydration qualitatively $[11,12]$ and their application to 3D problems often turns out to be very complicated. Another drawback of these techniques in the literature is to use ad hoc modifications and simple assumptions. In some of these techniques, a large number of tests to characterize the model inputs are required [12, 33]. Moreover, gradients/divergence terms in the governing equation could be a source of inconsistency with the onset of material discontinuity [34].

Peridynamic is a nonlocal approach firstly proposed by Silling et al. [35-37]; it paves the way to cope with the problems with discontinuity e.g. cracks in solid mechanics. In this approach, integral equations are employed rather than partial differential equations (PDEs) to determine the internal forces over the continuum. This approach has been widely applied to simulate many engineering problems with discontinuities (see for instance [38-42]). Moreover, peridynamic formulation has been developed for multiphysics problems such as thermal diffusion in [43-45]. A comprehensive investigation of thermal diffusion problems has been done by using a statebased peridynamics in [46]. Moreover, thermal shock cracking in brittle materials e.g. ceramics have been thoroughly explored by peridynamic approach in [47-52]. More recently, adaptive refinement techniques [47, 53-56], parallel computational tools [57] and coupling of peridynamic models with other models [58-60] have been developed to maintain the accuracy and to reduce the computational cost of peridynamic models. Other applications of peridynamic theory to simulate multiphysics problems can be traced in [61-66].

The main purpose of the present study is the solution of chemo-thermo-mechanical problems in cement based materials, including crack initiation and propagation, using a peridynamic based approach. In fact, the peridynamic approach offers some advantages [67, 68], in terms of accuracy and efficiency, which can be highly important for the coupled chemothermo-mechanical problems conducted in the present study. The proposed model includes, the effects of hydration reactions on the mechanical properties of material. The model exhibits highly accurate results, with respect to experiments in the literature, not only in terms of displacement but also in terms of crack path, temperature and hydration degree. One of the major advantages of the proposed approach is that there is no need to re-mesh the model when there are discontinuities such as cracks. These features culminate in a robust model that performs properly even in situations where the nucleation and propagation of cracks with complex patterns occurs.

The paper is structured as follows. Section 2 provides the fundamentals of all the interactions taken into account during the hydration process. A peridynamic based mathematical model is developed in section 3, while in sect. 4, we explain the step by step of the procedure of the algorithm. Model validation by using experimental data is shown in Sect. 5. In Sect. 6, the accuracy of the method is investigated by several examples. Section 7 concludes the paper.

\section{Fundamentals}

Let us consider a body which in an initial configuration $\Omega$ occupies a 2D space (see Fig. 1). By applying chemo-thermo-mechanical conditions on $\Omega$ or on its boundary, $\partial \Omega$, four state variables including displacement, $\mathbf{u}(\mathbf{x}, t)$, temperature $T(\mathbf{x}, t)$, hydration degree $\alpha(\mathbf{x}, t)$ and the damage level $\phi(\mathbf{x}, t)$ vary over the body. By calculating these four variables, one can determine the state of the whole system. The various fields are all interacting in this multi-physics model (see Fig. 2). In Fig. 2, each arrow represents the interaction direction e.g. chemical and thermal analysis influence the mechanical analysis because 


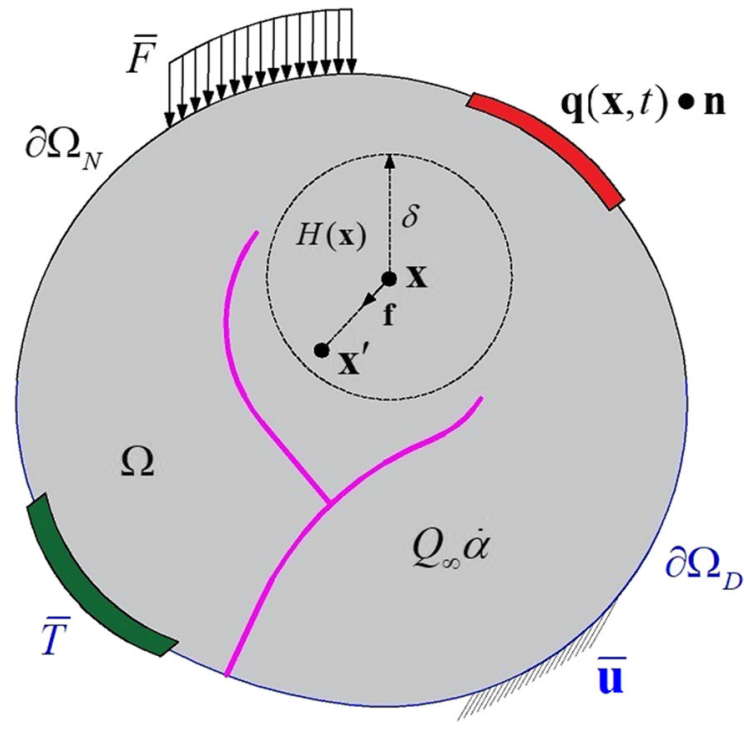

Fig. 1 A generic problem domain and representation of interaction domain $H(\mathbf{x})$, source $(\mathbf{x})$ and neighboring material points $\left(\mathbf{x}^{\prime}\right)$ in Peridynamics

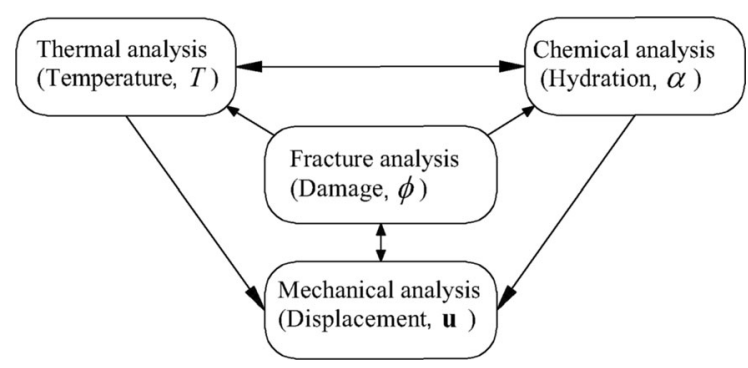

Fig. 2 Chemo-thermo-mechanical interactions

variations in temperature and hydration affect the displacements and therefore may generate cracks. On the other hand crack propagation determines a variation of thermal conductivity and of hydration which is the only influence mechanics has on the thermal and hydration fields. This implies that, fracture analysis is the direct result of the mechanical analysis and we use the fracture effect by using a history-dependent function which is discussed later in the mechanical kernel function.

In order to analyse this multi-physics model through an appropriate scheme, we decouple it into two main problems as follows:

1. Fully coupled chemo-thermal problem

2. Chemo-thermo-mechanical coupled problem
In the next section, we explain how Peridynamics is used to solve the aforementioned problems.

\section{Mathematical model}

This section shows the equations adopted to study the multi-physics model using the peridynamic approach.

\subsection{Fully coupled chemo-thermal problem}

Based on Fourier's law, the thermodynamic equilibrium of thermal flux in a concrete specimen due to hydration reaction is governed by:

$\rho c_{v} \dot{T}=\nabla(k \nabla T)+Q_{\infty} \dot{\alpha}$

in which, $\rho$ and $c_{v}$ are the density of the material and the specific heat capacity. $Q_{\infty}$ stands for the potential heat of the hydration reaction and $\alpha$ is the hydration degree which describes the level of the hydration reaction between cement and water. $\alpha$ takes a value between 0 and $1,0 \leqslant \alpha \leqslant 1 . \alpha=1$ means full hydration between cement and water takes place. Furthermore, $T$ and $k$ represent the temperature and the thermal conductivity respectively. Considering a constant value for thermal conductivity, Eq. (1) takes the following form:

$\rho c_{v} \dot{T}=k \nabla^{2} T+Q_{\infty} \dot{\alpha}$

Bobaru and Duangpanya [44] firstly proposed the application of the Bond Based Peridynamics (BB-PD) to heat conduction problem. The heat flux is exchanged between a material point $\mathbf{x}$ (the source node) and the family points located within its integration domain; i.e, $\mathbf{x}^{\prime} \in H(\mathbf{x})$ as shown in Fig. 1. Hence, the transient form of the BB-PD thermal diffusion equation is expressed by:

$$
\rho c_{v} \dot{T}(x, t)=\int_{H(\mathbf{x})} f_{h}\left(T^{\prime}, T, \mathbf{x}^{\prime}, \mathbf{x}\right) d V_{\mathbf{x}^{\prime}}+h_{s}(\mathbf{x}, t)
$$

in which $h_{s}(\mathbf{x}, t)$ is the heat source per unit volume and the kernel function, $f_{h}$, is given by Chen and Bobaru [69]:

$f_{h}\left(T^{\prime}, T, \mathbf{x}^{\prime}, \mathbf{x}\right)=c_{T H} \frac{\tau\left(\mathbf{x}^{\prime}, \mathbf{x}, t\right)}{\|\xi\|^{n}}$

where 


$$
\tau\left(\mathbf{x}^{\prime}, \mathbf{x}, t\right)=T\left(\mathbf{x}^{\prime}, t\right)-T(\mathbf{x}, t)
$$

In BB-PD, two material points have the relative position $\boldsymbol{\xi}=\mathbf{x}-\mathbf{x}^{\prime}$ known as bond. We assume that the heat flux depends on the temperature difference between the points and it occurs over a bond connecting two material points. In Eq. (4), $c_{T H}$ stands for the thermal micro-conductivity in peridynamics correlated with the standard conductivity. This correlation can be obtained by equating the classical thermal potential to the peridynamic thermal potential at a material point with a specific horizon size, $\delta$, (the details can be found in $[45,46])$. The so-called horizon specifies the size of the region where non-local interactions occur. In Eq. (4), $n$ is an integer, normally selected to be 0,1 , or 2 [44-46]. Based on [69], different values of $n$ in the representation of the kernel function have been selected in the past. For example, a constructive approach to derive the specific form of the kernel function leads to $n=2$ (see [44, 45]). The value $n=1$ is used in [46], and this value has been used most often for the mechanical peridynamic formulation [70]. A comprehensive study on different values of $n$ can be found in [69]. In this paper, $n=1$ is used as suggested in [46]. Furthermore, the thermal micro-modulus $c_{T H}$ can be represented in terms of the thermal conductivity $k$ for $1 \mathrm{D}, 2 \mathrm{D}$ and $3 \mathrm{D}$ cases as:

$$
c_{T H}= \begin{cases}\frac{2 k}{A \delta^{2}}, & 1 \mathrm{D} \\ \frac{6 k}{\pi \bar{t} \delta^{3}}, & 2 \mathrm{D} \\ \frac{6 k}{\pi \delta^{4}}, & 3 \mathrm{D}\end{cases}
$$

where $\bar{t}$ and $A$ stand for thickness of the body (2D case) and the cross-sectional area allocated to each material point, respectively. In the coupled chemo-thermal problem, the heat source per unit volume $h_{s}(\mathbf{x}, t)$ is due to hydration reaction and Eq. (2) can be rewritten as:

$$
\rho c_{v} \dot{T}(\mathbf{x}, t)=\int_{H(\mathbf{x})} f_{h}\left(T^{\prime}, T, \mathbf{x}^{\prime}, \mathbf{x}\right) d V_{\mathbf{x}^{\prime}}+Q_{\infty} \dot{\alpha}
$$

In Eq. (7), we assume that the evolution of heat release due to the hydration process is obtained by the Arrhenius law [23]. The heat released during hydration reaction is defined by:

$$
Q_{\infty} \dot{\alpha}=(1-\phi) A_{T} f(\alpha) e^{\left(\frac{-E_{a}}{R T}\right)}
$$

where $A_{T}$ represents the ratio of the maximum value of the heat production rate to the latent hydration heat for a normalized definition of the hydration function $[1,29,32]$, the damage variable $\phi$ affects the heat during hydration reaction as assumed in [29]. Moreover, $E_{a}$ is the activation energy characterizing the rate of heat generation and $R=8.314 \times 10^{-3}$ $\mathrm{kJ} \mathrm{K}^{-1} \mathrm{~mol}^{-1}$ is the ideal gas constant. In Eq. (8), $\phi$ stands for the damage level of point $\mathbf{x}$ which is described in the next section where the fracture analysis effects are introduced in the chemo-thermomechanical problem. In fact, $\phi$ in Eq. (8) takes a value between 0 and 1 . Moreover, $f(\alpha)$ is the evolution function providing the normalized heat production rate in terms of the hydration degree. Generally, there are many ways to choose this specific function e.g. a piecewise linear or exponential approximation of the experimental data $[1,20,29,33,71]$. In the present study, the power form of the evolution function, $f(\alpha)$, for the normalized heat production rate is considered as presented in [1, 29, 32]:

$f(\alpha)=\left(\frac{\alpha}{a}\right)^{b}\left(\frac{1-\alpha}{1-a}\right)^{c}$

The constants $a, b$ and $c$ in Eq. (9) are determined by interpolating experimental data [29]. The relation between the aforementioned constants is expressed as [20, 29, 32, 71]:

$a c=(1-a) b, \quad b<1$

We can discretize Eq. (7) in different ways [72]. In this contribution, the discretization is performed by a meshfree approach originally introduced in [36]; this simple discretization have been commonly applied in the literature (see Fig. 3).

In $2 \mathrm{D}$ cases, the domain is discretized by a grid of points known as nodes. We assign a volume equal to $\Delta x^{2} \bar{t}$ to each node, where $\bar{t}$ is the specimen thickness. In this way, each node is located in a center of a square cell as depicted in Fig. 3. Each node $\mathbf{x}_{i}$ interacts with all the nodes within its integration domain as shown in Fig. 3. Hereinafter, $\mathbf{x}_{i}$ and $\mathbf{x}_{j}$ are called the source node and the family node, respectively. The horizon is considered as $\delta=m \Delta x$, where $m$ is the ratio between $\delta$ and the grid size $\Delta x$. In the usual way, $\delta, m$ and $\Delta x$ are considered uniform in the whole domain. 


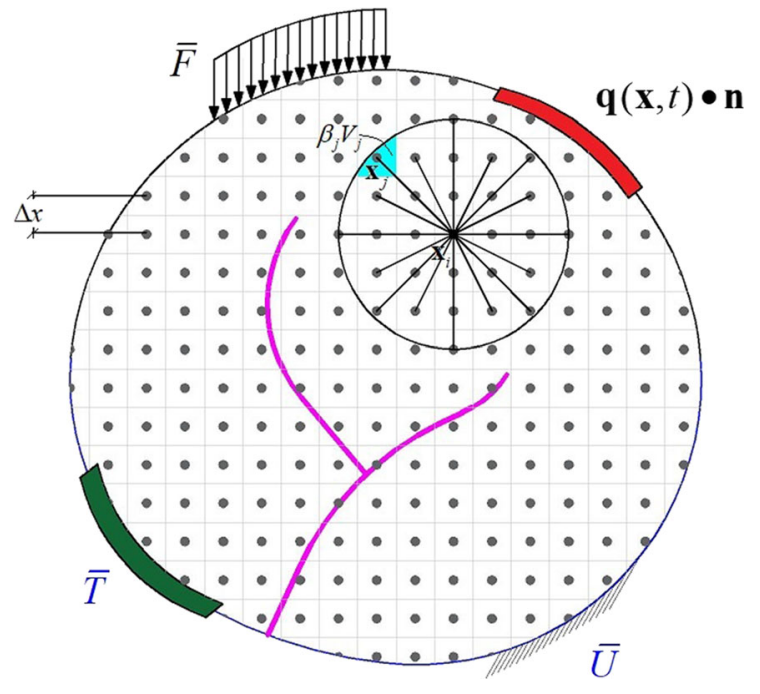

Fig. 3 Peridynamic nodes and their interactions

Moreover, one can discretize the time into instants as $t_{1}, t_{2}, \ldots, t_{n}$.

Therefore, by choosing the one-point Gauss quadrature rule for the integration in space, one can express the discretized form of Eq. (7) as:

$\rho c_{v} \dot{T}_{i}^{n}=\sum_{j=1}^{N} f_{h}\left(\tau^{n}\left(\mathbf{x}_{j}-\mathbf{x}_{i}\right)\right) \beta\left(\mathbf{x}_{j}-\mathbf{x}_{i}\right) V_{j}+Q_{\infty} \dot{\alpha}$

where $V_{j}$ stands for the volume of node $\mathbf{x}_{j}$ and $N$ represents the total number of family nodes.

Finally, $\beta\left(\mathbf{x}_{j}-\mathbf{x}_{i}\right)$ is the volume correction factor which determines the portion of $V_{j}$ that falls within the interaction domain of source node $\mathbf{x}_{i}$. In this paper, $\beta\left(\mathbf{x}_{j}-\mathbf{x}_{i}\right)$ is determined as suggested in [73].

To solve Eq. (11), different time integration schemes can be taken into account. In this paper, we employ a forward difference time marching; in this way, after obtaining the field variables $\left(\alpha_{i}^{n}\right.$ and $\left.T_{i}^{n}\right)$ at time instant $t_{n}$, one is able to advance to the next time step via set of coupled equations as follows:

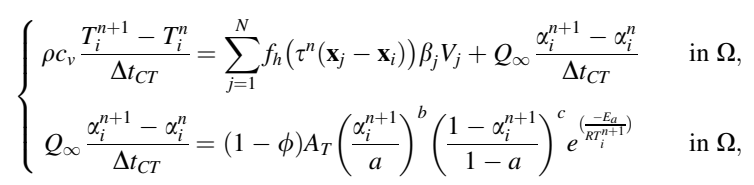

The unknown values in Eq. (12), are $T_{i}^{n+1}$ and $\alpha_{i}^{n+1}$. Various techniques can be used to solve Eq. (12), in this study, the Newton Raphson (N-R) method is adopted. In Eq. (12), $\Delta t_{C T}$ is the incremental time step related to the chemo-thermal analysis, to obtain a stable solution we must choose it within a proper range. The upper bound of the range can be expressed by $[36,46]$ :

$$
\Delta t_{C T}<\frac{\rho c_{v}}{\sum_{j=1}^{N} \frac{c_{T H}}{\|\xi\|} V_{j}}
$$

\subsubsection{Boundary conditions}

Chemo-thermal boundary conditions of Dirichlettype, must be applied on corresponding boundary surfaces represented by $\partial \Omega_{D}$. For this type of conditions, a temperature field should be assigned to each node located within a distance $\Delta x / 2$ close to $\partial \Omega_{D}$ (Fig. 1); however, Neumann-type boundary conditions is imposed in the form of convection, heat flux and radiation. To impose heat flux boundary conditions, firstly we evaluate the rate of heat entering into the body from the boundary surface, then we must convert the rate of flowing heat $\dot{Q}$ to a volumetric value $\tilde{Q}$ (heat generation per unit volume) by [45]:

$$
\tilde{Q}=\frac{\dot{Q}}{V_{f}}=-\frac{\int_{S} \mathbf{q} \cdot \mathbf{n} d s}{S \Delta x}=-\frac{\mathbf{q} \cdot \mathbf{n}}{\Delta x}, \quad \mathbf{x} \in \partial \Omega_{N}
$$

in which, $\mathbf{q}$ is the heat flux, $S$ is the area to which the heat flux is imposed and $V_{f}$ is the volume of the boundary region. By using Eq. (14), one can determine the heat flux portion of each node on the corresponding boundary.

The convection boundary condition (Neumann), in which a heat transfer between the surface of a body and its surrounding occurs, is expressed by [45, 46]:

$$
q(\mathbf{x}, t) \cdot \mathbf{n}=h\left(T_{s}(\mathbf{x}, t)-T_{a}(\mathbf{x}, t)\right), \quad \mathbf{x} \in \partial \Omega_{N}
$$

in which $h$ is the convective heat transfer coefficient. Moreover, $T_{s}(\mathbf{x}, t)$ and $T_{a}(\mathbf{x}, t)$ are the body surface and air temperature, respectively. In this way, volumetric heat generation due to the convection boundary condition is defined by [45]:

$$
h_{s}(\mathbf{x}, t)=h\left(T_{s}(\mathbf{x}, t)-T_{a}(\mathbf{x}, t)\right), \quad \mathbf{x} \in \partial \Omega_{N}
$$

For the chemical part, a Neumann-type boundary condition is assigned to the hydration degree $(\alpha)$; 
furthermore, the initial value of the hydration degree needs to be prescribed on the whole domain.

In the next subsection, we illustrate the strategy to cope with the mechanical part of solution, using Peridynamics. The same discretization scheme in space is used in the mechanical solution. Therefore, we describe how to incorporate the chemo-thermal effects into the mechanical solution.

\subsection{Chemo-thermo-mechanical coupled problem}

In this subsection, the basic concepts in addition to the main ideas of the peridynamic model for fracture are presented. Let us consider again a body, which an initial configuration $\Omega$, occupies a $2 \mathrm{D}$ space (see Fig. 4). Based on BB-PD, the equation of motion is given by:

$$
\rho(\mathbf{x}) \ddot{\mathbf{u}}(\mathbf{x}, t)=\int_{H(\mathbf{x})} \mathbf{f}\left(\mathbf{u}\left(\mathbf{x}^{\prime}, t\right)-\mathbf{u}(\mathbf{x}, t), \mathbf{x}^{\prime}-\mathbf{x}\right) d V_{\mathbf{x}^{\prime}}+\mathbf{b}(\mathbf{x}, t)
$$

where $\mathbf{f}$ stands for the pairwise force function of each bond and similar to the chemo-thermal problem, two material points interact only within a finite distance, $\delta$. Moreover, $\rho, \mathbf{u}$ and $\mathbf{b}$ are the mass density, displacement field and body force density, respectively. In Eq. (17), the position of point $\mathbf{x}$ at time $t$ is denoted by $\mathbf{y}(\mathbf{x}, t)=\mathbf{x}+\mathbf{u}(\mathbf{x}, t)$. In Fig. 4, the relative displacement vector between two points is defined as $\boldsymbol{\eta}=\mathbf{u}^{\prime}-\mathbf{u}$. By using a constitutive law, with the Prototype Microelastic Brittle (PMB) model [36], the pairwise force function is expressed by:

$$
\begin{aligned}
& \mathbf{f}\left(\mathbf{u}^{\prime}-\mathbf{u}, \mathbf{x}^{\prime}-\mathbf{x}, t\right)=\mu(\boldsymbol{\xi}, t) c_{M E}(\alpha) \omega(\boldsymbol{\xi}) \\
& \left(s-\beta^{\prime} \Delta T_{a v g}+\kappa\left\langle\frac{\Delta \alpha_{a v g}-\alpha_{a u}}{1-\alpha_{a u}}\right\rangle_{+}\right) \frac{\mathbf{y}\left(\mathbf{x}^{\prime}, t\right)-\mathbf{y}(\mathbf{x}, t)}{\left\|\mathbf{y}\left(\mathbf{x}^{\prime}, t\right)-\mathbf{y}(\mathbf{x}, t)\right\|} \\
& </ \text { script }></ \text { div }><\text { divclass } \\
& =\text { "EquationNumber" }>18</ \text { div }></ \text { div }>\text { where }<\text { divid } \\
& =\text { "IEq142" class }=\text { "InlineEquation" }><\text { divformat } \\
& =\text { "TEX" } i d=" 11012_{2} 021_{1} 375_{I} \text { Eq142" class } \\
& =\text { "mathinline" name = "EquationSource" onclick } \\
& =\text { "OpenMathWindow ('11012 } 2021_{1} 375_{I} \text { Eq142');" title } \\
& =\text { "Clickheretoedit" }><\text { scripttype }=\text { "math } / \text { tex } ; \text { mode }=\text { inline" }> \\
& <!\left[C D A T A \left[\beta^{\prime}\right.\right.
\end{aligned}
$$

is the thermal expansion coefficient and $s$ denotes the relative elongation (stretch) of a bond, defined by [35]:

$$
s=\frac{\|\boldsymbol{\xi}+\boldsymbol{\eta}\|-\|\boldsymbol{\xi}\|}{\|\boldsymbol{\xi}\|}
$$

In Eq. (18), the average temperature of a bond is defined by:

$$
\Delta T_{a v g}=\frac{\left(T-T_{0}\right)+\left(T^{\prime}-T_{0}\right)}{2}
$$

where $T_{0}$ represents the reference temperature, $T$ and $T^{\prime}$ indicate the temperature at material points $\mathbf{x}$ and $\mathbf{x}^{\prime}$ respectively. Similarly, the average level of hydration degree is expressed as:

$$
\Delta \alpha_{a v g}=\frac{\left(\alpha-\alpha_{0}\right)+\left(\alpha^{\prime}-\alpha_{0}\right)}{2}
$$

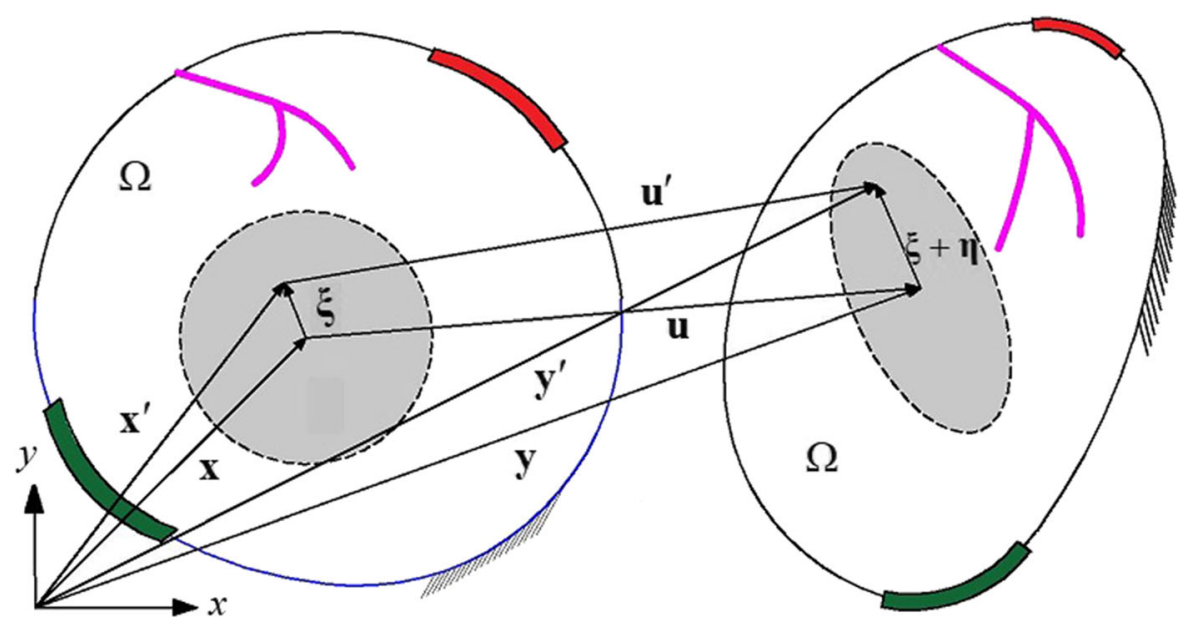

Fig. 4 Kinematics of the reference and deformed configurations for a peridynamic continuum 
Table 1 Material properties of the concrete C20/251 (Ref. [1])

\begin{tabular}{llll}
\hline Parameter & Value & Parameter & Value \\
\hline$k$ & $2.636 \mathrm{~W} /(\mathrm{m} \mathrm{K})$ & $\alpha_{a u}$ & 0.01 \\
$\rho c_{v}$ & $2536.51 \mathrm{~kJ} /\left(\mathrm{K} \mathrm{m}^{3}\right)$ & $\alpha_{E}$ & 0.01 \\
$Q_{\infty}$ & $124,014 \mathrm{~kJ} / \mathrm{m}^{3}$ & $\alpha_{G_{0}}$ & 0.01 \\
$\beta^{\prime}$ & $10 \mu \mathrm{m} /(\mathrm{m} \mathrm{K})$ & $E_{a}$ & $51.53 \mathrm{~kJ} / \mathrm{mol}$ \\
$\kappa$ & $200 \mu \mathrm{m} / \mathrm{m}$ & $v$ & 0.2 \\
$E_{\infty}$ & $30 \mathrm{GPa}$ & $h$ & $8 \mathrm{~W} /\left(\mathrm{m}^{2} \mathrm{~K}\right)$ \\
$G_{0 \infty}$ & $164.5 \mathrm{~N} / \mathrm{m}$ & $A_{T}$ & $3.6 \mathrm{GW} / \mathrm{kg}$ \\
$\mathrm{a}$ & 0.149 & $\mathrm{~b}$ & 0.51 \\
$\mathrm{c}$ & 2.91 & $m$ & 3 \\
\hline
\end{tabular}

where $\alpha_{0}$ represents the reference hydration degree, $\alpha$ and $\alpha^{\prime}$ indicate the hydration degree at material points $\mathbf{x}$ and $\mathbf{x}^{\prime}$ respectively.

The material constant $\kappa$, in Eq. (18) denotes the evaluation of autogenous shrinkage when hydration degree is greater than the mechanical percolation threshold $\alpha_{a u}$ and the $\langle\cdot\rangle_{+}$represents the positive operator [29]. To take into account the shrinkage effect of hydration phenomenon, $\kappa\left\langle\frac{\Delta \alpha_{a v g}-\alpha_{a u}}{1-\alpha_{a u}}\right\rangle_{+}$in Eq. (18) has been introduced. Moreover, $\mu(\xi, t)$ is a history-dependent function which takes the value of 0 for broken bonds and 1 for active bonds. $c_{M E}(\alpha)$ stands for the micro-modulus defined in Eq. (22). $\omega(\xi)$ determines the degree of interactions between points. Taking into account the elastic deformation energy and $\omega(\xi)=1$, one is able write the mechanical micro-

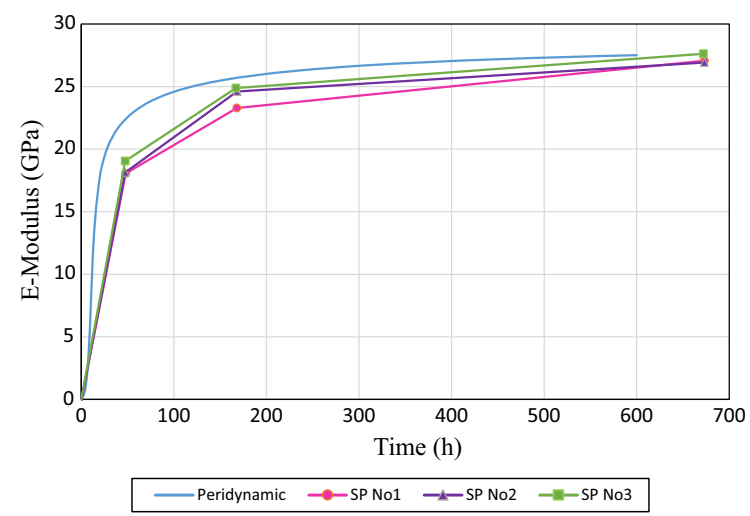

Fig. 5 Evolution of the elastic modulus during the hydration process

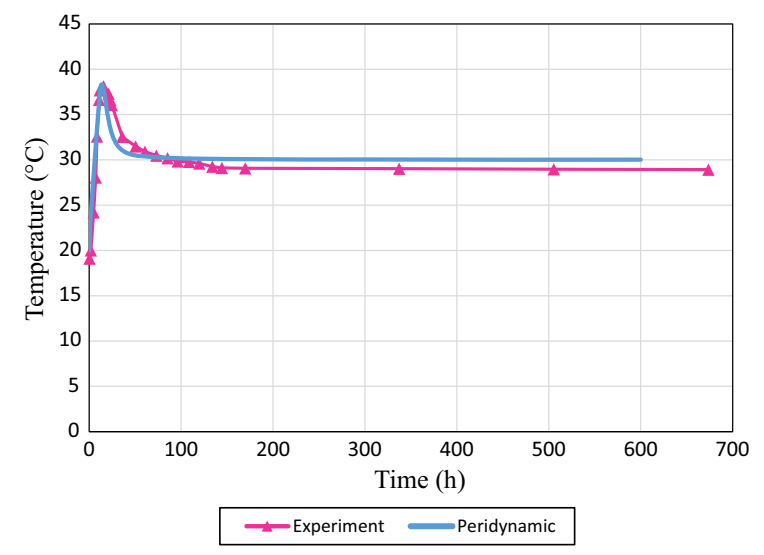

Fig. 6 Temperature evolution obtained during the hydration process

modulus in terms of the horizon radius $\delta$ and of the Young's modulus $E$ and as:

$c_{M E}(\alpha)= \begin{cases}\frac{9 E(\alpha)}{\pi \bar{t} \delta^{3}}, & \text { Plane stress } \\ \frac{48 E(\alpha)}{5 \pi \bar{t} \delta^{3}}, & \text { Plane strain } \\ \frac{12 E(\alpha)}{\pi \delta^{4}}, & 3 D\end{cases}$

Moreover, the critical stretch, $s_{0}(\alpha)$, is defined in terms of the critical energy release rate of the material, $G_{0}(\alpha) \quad[36,44]$ :

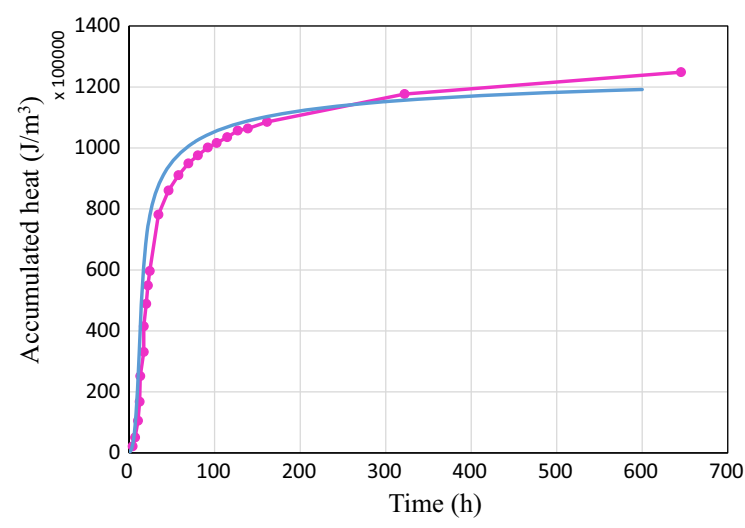

-Experiment $\longrightarrow$ Peridynamic

Fig. 7 Time-history of the accumulated heat during the hydration process 


$$
s_{0}(\alpha)= \begin{cases}\sqrt{\frac{4 \pi G_{0}(\alpha)}{9 E(\alpha) \delta},} & \text { Plane stress } \\ \sqrt{\frac{5 \pi G_{0}(\alpha)}{12 E(\alpha) \delta},} & \text { Plane strain } \\ \sqrt{\frac{5 G_{0}(\alpha)}{6 E(\alpha) \delta}}, & 3 D\end{cases}
$$

Due to the processes that occur in the hardening cement paste, its mechanical properties are strongly affected by the hydration value $\alpha[1,29]$, since in the previous formula the mechanical parameters depend on the hydration value. The Young's modulus, $E(\alpha)$ and the critical energy release rate, $G(\alpha)_{0}$, are given by $[1,29]$ :

$$
\left\{\begin{aligned}
E(\alpha) & =E_{\infty} \bar{\alpha}^{\alpha_{E}} \\
G_{0}(\alpha) & =G_{0 \infty} \bar{\alpha}^{\alpha_{G_{0}}}
\end{aligned}\right.
$$

where $E_{\infty}$ and $G_{0 \infty}$ are the final Young's modulus and final (when the hydration is completed) energy release rate, respectively. $\bar{\alpha}^{\alpha_{E}}$ and $\bar{\alpha}^{\alpha_{G_{0}}}$ are two parameters in the range of $(0,1)$ related with the hydration value of the material $\alpha$. Based on $[24,29,74], \bar{\alpha}^{\alpha_{E}}, \bar{\alpha}^{\alpha_{G_{0}}}$ are defined by:

$$
\bar{\alpha}^{\alpha_{E}}=\left\langle\frac{\alpha-\alpha_{E}}{1-\alpha_{E}}\right\rangle_{+}
$$

and

$$
\bar{\alpha}^{\alpha_{G_{0}}}=\left\langle\frac{\alpha-\alpha_{G_{0}}}{1-\alpha_{G_{0}}}\right\rangle_{+}
$$

where $\alpha_{E}$ and $\alpha_{G_{0}}$ are two threshold hydration degree constants, which express the hydration degree when material starts having both the mechanical properties,

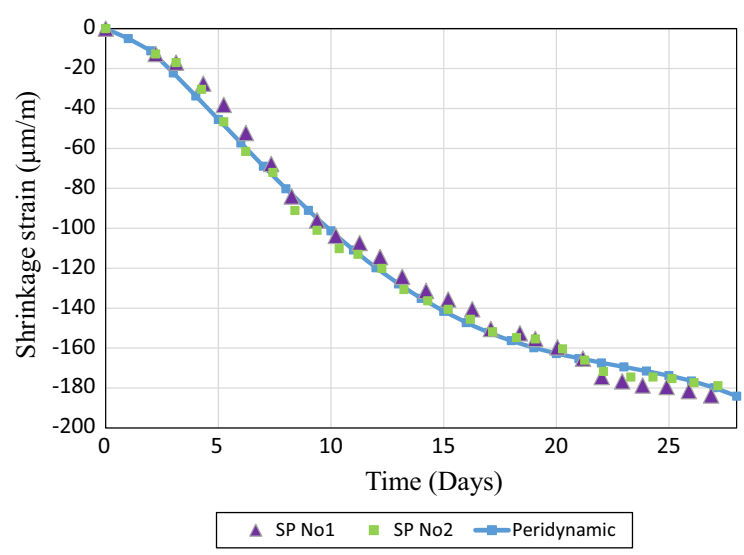

Fig. 9 Evolution of shrinkage strain in concrete C20/25

$E(\alpha)$ and $G_{0}(\alpha)$ greater than zero. We break a bond and remove it from further calculations when:

$$
s-\beta^{\prime} T_{a v g}+\kappa\left\langle\frac{\Delta \alpha_{a v g}-\alpha_{a u}}{1-\alpha_{a u}}\right\rangle_{+} \geqslant s_{0}(\alpha)
$$

Moreover, the damage level of point $\mathbf{x}$ at time $t$ is given by:

$$
\phi(\mathbf{x}, t)=1-\frac{\int_{H(\mathbf{x})} \mu(\boldsymbol{\xi}, t) d V_{\mathbf{x}^{\prime}}}{\int_{H(\mathbf{x})} d V_{\mathbf{x}^{\prime}}}
$$

where $\phi$ represents the ratio of the number of broken bonds to the total number of bonds initially connected to point $\mathbf{x}$ and its value is between 0 and 1 . The case $\phi=0$ means that there is no broken bonds between the point and all surrounding points within its horizon, while $\phi=1$ represents a complete damaged state.

It is well known that PBM constitutive law may lead to overstimations of the peak-load [75-78] and to difficulties in the capability to describe the post-peak
Fig. 8 Evolution of the room temperature during the whole testing period $[1,83]$

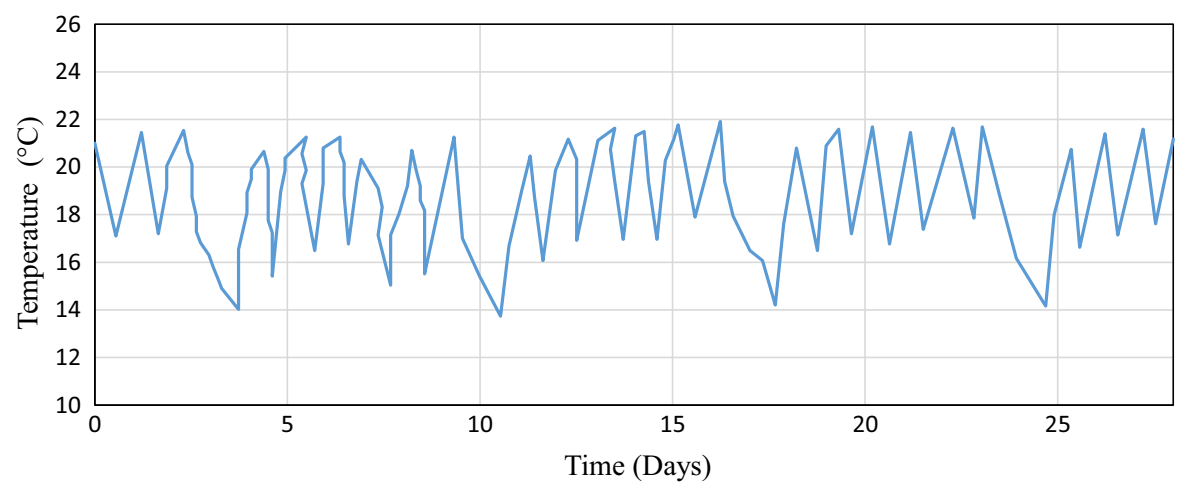




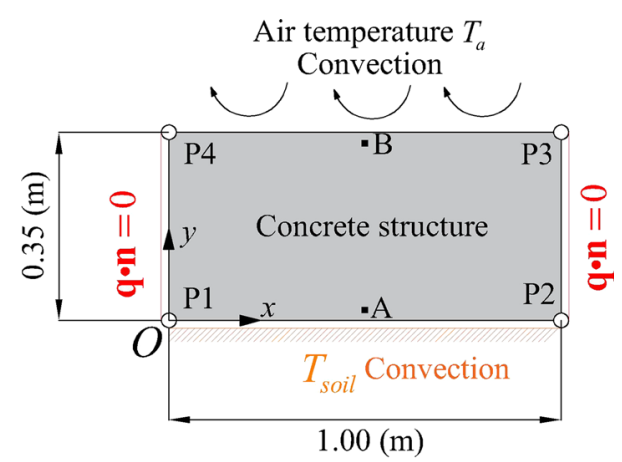

Fig. 10 Example I: concrete slab restrained by supporting piles: problem domain and boundary conditions

behaviour. A possible strategy for reducing this effect is to adopt bi or tri-linear constitutive laws or nonuniform material resistance as indicated in [79].

Similar to the chemo-thermal part, to discretize Eq. (17), one can adopt the one-point Gauss quadrature rule as:

$$
\begin{aligned}
\rho(\mathbf{x}) \ddot{\mathbf{u}}(\mathbf{x}, t)= & \sum_{j=1}^{N} \mathbf{f}\left(\mathbf{u}\left(\mathbf{x}^{\prime}, t\right)-\mathbf{u}(\mathbf{x}, t), \mathbf{x}^{\prime}-\mathbf{x}\right) \\
& \beta\left(\mathbf{x}_{j}-\mathbf{x}_{i}\right) V_{j}+\mathbf{b}(\mathbf{x}, t)
\end{aligned}
$$

In the present contribution, a quasi-static solution is obtained using the dynamic relaxation method firstly introduced in [80]. As suggested in [81, 82], the equation of motion of each node in Eq. (29) is assembled, into a global system of equations and therefore one can introduce an artificial damping to the system by:

Table 2 Example I material properties (Refs. [29, 31])

\begin{tabular}{llll}
\hline Parameter & Value & Parameter & Value \\
\hline$k$ & $2.6 \mathrm{~W} /(\mathrm{m} \mathrm{K})$ & $\alpha_{a u}$ & 0.115 \\
$\rho c_{v}$ & $2400 \mathrm{~kJ} /\left(\mathrm{K} \mathrm{m}^{3}\right)$ & $\alpha_{E}$ & 0 \\
$Q_{\infty}$ & $119,000 \mathrm{~kJ} / \mathrm{m}^{3}$ & $E_{a}$ & $50 \mathrm{~kJ} / \mathrm{mol}$ \\
$\beta^{\prime}$ & $10 \mu \mathrm{m} /(\mathrm{m} \mathrm{K})$ & $v$ & 0.2 \\
$\kappa$ & $30 \mu \mathrm{m} / \mathrm{m}$ & $T_{\text {Soil }}$ & $17^{\circ} \mathrm{C}$ \\
$E_{\infty}$ & $29 \mathrm{GPa}$ & $A_{T}$ & $0.729 \mathrm{GW} / \mathrm{kg}$ \\
$h_{1-2}$ & $4.5 \mathrm{~W} /\left(\mathrm{m}^{2} \mathrm{~K}\right)$ & $h_{3-4}$ & $7.5 \mathrm{~W} /\left(\mathrm{m}^{2} \mathrm{~K}\right)$ \\
$\mathrm{a}$ & 0.149 & $\mathrm{~b}$ & 0.51 \\
$\mathrm{c}$ & 2.91 & $m$ & 3 \\
\hline
\end{tabular}

$$
\boldsymbol{\Lambda} \mathbb{E}(\mathbf{X}, t)+C \boldsymbol{\Lambda} \boldsymbol{U}(\mathbf{X}, t)=\mathbf{F}\left(\mathbf{U}, \mathbf{U}^{\prime}, \mathbf{X}, \mathbf{X}^{\prime}\right)
$$

in which $C$ stands for the damping coefficient and $\boldsymbol{\Lambda}$ is the fictitious diagonal density matrix. Furthermore, displacement vector $\mathbf{U}$ and the positions vector, $\mathbf{X}$ in Eq. (30) are given by:

$$
\begin{aligned}
& \mathbf{U}=\left[\mathbf{u}\left(\mathbf{x}_{1}, t\right), \mathbf{u}\left(\mathbf{x}_{2}, t\right), \ldots, \mathbf{u}\left(\mathbf{x}_{M}, t\right)\right] \\
& \mathbf{X}=\left[\mathbf{x}_{1}, \mathbf{x}_{2}, \ldots, \mathbf{x}_{M}\right]
\end{aligned}
$$

Moreover, $\mathbf{F}$ stands for the summation of the external and internal forces, whose its $i$-th component can be calculated:

$$
\begin{aligned}
F_{i}=\sum_{i=1}^{M} & \sum_{j=1}^{N} \mathbf{f}\left(\mathbf{u}\left(\mathbf{x}_{j}, t\right)-\mathbf{u}\left(\mathbf{x}_{i}, t\right), \mathbf{x}_{j}-\mathbf{x}_{i}\right) \beta\left(\mathbf{x}_{j}-\mathbf{x}_{i}\right) V_{j} \\
& +\mathbf{b}\left(\mathbf{x}_{i}, t\right)
\end{aligned}
$$

where $M$ is the total number of nodes, and the density matrix, $\boldsymbol{\Lambda}$, is defined according to [81]. For the damping ratio $C$, values in the range of $10^{6}-10^{7}$ $\mathrm{kg} / \mathrm{m}^{3} \mathrm{~s}$ are used, as suggested in [82].

The time integration is performed by adopting a central difference explicit integration approach. Having found the displacement and acceleration of each node $\mathbf{x}_{i}$ at $t^{n},\left(\mathbf{u}_{i}^{n}, \ddot{\mathbf{u}}_{i}^{n}\right)$, displacements and velocities at $t^{n+1}=t^{n}+\Delta t_{M E}$ can be calculated by:

$$
\begin{aligned}
& \dot{\mathbf{u}}_{i}^{n+1 / 2}=\frac{\left(2-C \Delta t_{M E}\right) \dot{\mathbf{u}}_{i}^{n-1 / 2}+2 \Delta t_{M E} \Lambda_{i}^{-1} \mathbf{F}_{i}^{n}}{2+C \Delta t_{M E}} \\
& \mathbf{u}_{i}^{n+1}=\mathbf{u}_{i}^{n}+\Delta t_{M E} \dot{\mathbf{u}}_{i}^{n+1 / 2} \\
& \dot{\mathbf{u}}_{i}^{n+1}=\dot{\mathbf{u}}_{i}^{n+1 / 2}+\frac{\Delta t_{M E}}{2} \ddot{\mathbf{u}}_{i}^{n+1}
\end{aligned}
$$

In this way, the solver is able to advance to the next time step by:

$$
\mathbf{u}_{i}^{n+1}=\mathbf{u}_{i}^{n}+\Delta t_{M E} \dot{\mathbf{u}}_{i}^{n}+\frac{1}{2} \Delta t_{M E}^{2} \ddot{\mathbf{u}}_{i}^{n}
$$

in which $\Delta t_{M E}$ represents the constant mechanical time step. For the first time iteration, the velocity at $t^{1 / 2}$ is obtained by:

$$
\dot{\mathbf{u}}_{i}^{1 / 2}=\frac{1}{2} \Delta t_{M E} \boldsymbol{\Lambda}_{i}^{-1} \mathbf{F}_{i}^{0}
$$


Fig. 11 Time history of temperature $\mathrm{T}\left({ }^{\circ} \mathrm{C}\right)$ of $\mathbf{a}$ node $\mathbf{x}_{B}$ and $\mathbf{b}$ node $\mathbf{x}_{A}$
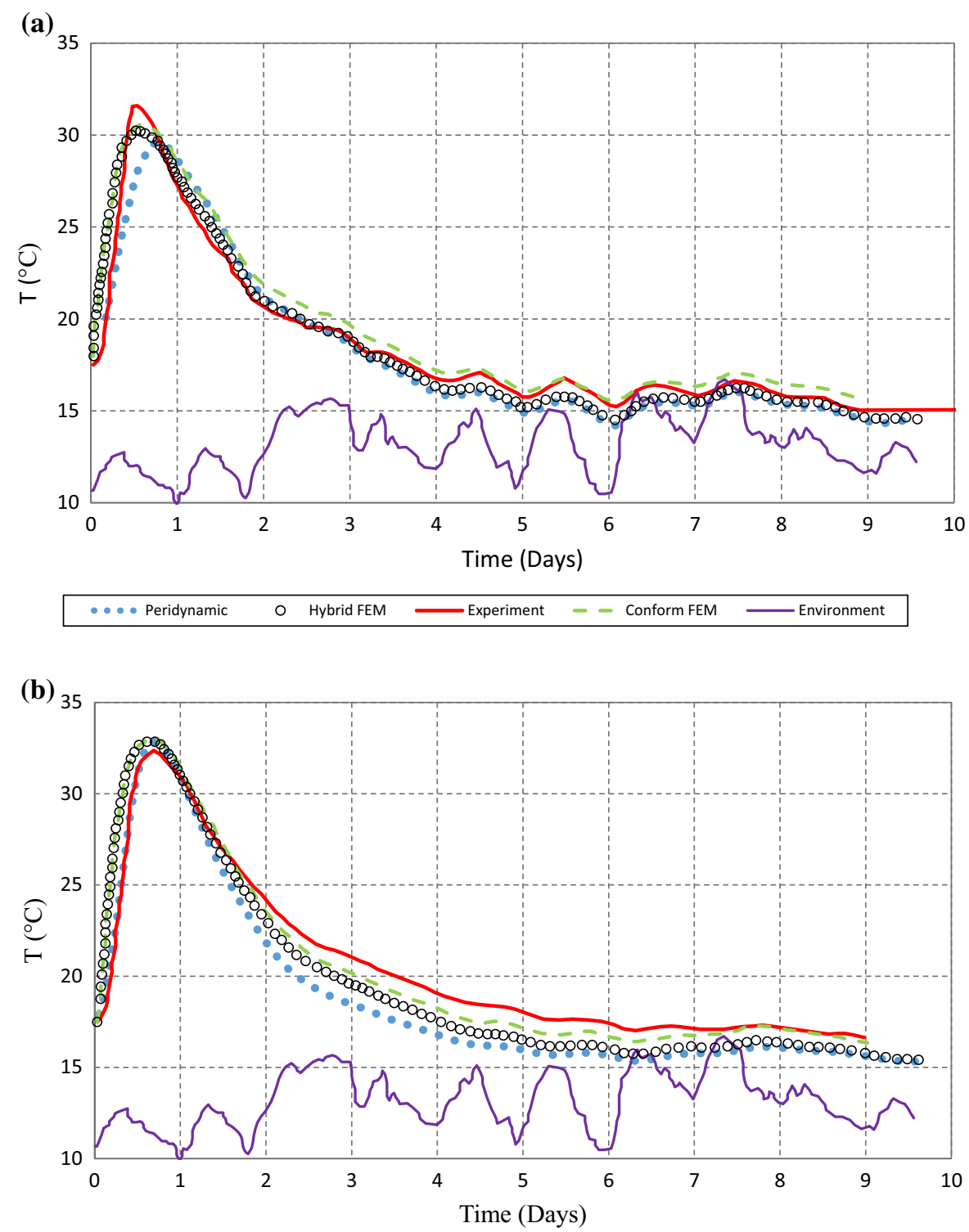

$\ldots$ Peridynamic $\quad \circ$ Hybrid FEM $\longrightarrow$ Experiment -- Conform FEM $\longrightarrow$ Environment
For the dynamic relaxation method, as recommended in [81] the time step is taken as $\Delta t_{M E}=1$.

\section{The step by step procedure of the method}

1. Inputting the constant parameters.

- Mechanical constants: $E_{\infty}, G_{0 \infty}, \alpha_{E}, \alpha_{G_{0}}, v, \rho, \Delta t_{M E}, \delta, c_{M E}$.
- Thermal constants: $c_{v}, \beta^{\prime}, k, h, T_{0}, T_{\infty}, \Delta t_{T H}, \delta, c_{T H}$.

- Chemical constants: $\alpha_{0}, Q_{\infty}, \kappa, \alpha_{a u}, A_{T}, E_{a}$.

2. Pre-processing: applying the chemical, thermal and mechanical initial conditions.

3. Chemo-thermal analysis for step $(n+1)$ and calculate $T^{n+1}$ and $\alpha^{n+1}$ by Eq. (12).

4. Calculate the displacements of the nodes through Eqs. (30)-(38).

5. Evaluate the stretch of the bonds by Eq. (19). 


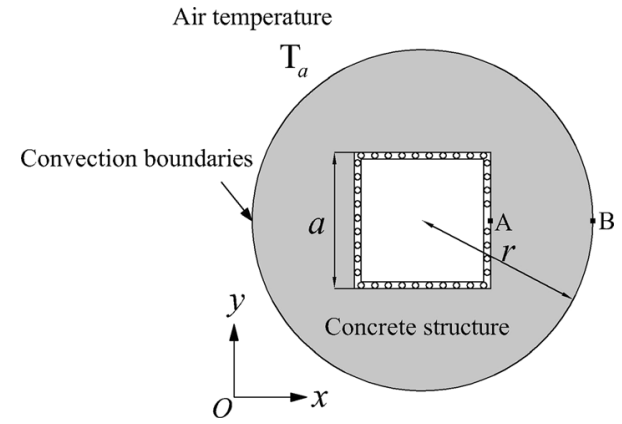

Fig. 12 Example II: geometry and boundary conditions for the hydration reaction in a cement ring structure

Table 3 Example II material properties (Ref. [29])

\begin{tabular}{llll}
\hline Parameter & Value & Parameter & Value \\
\hline$k$ & $2.8 \mathrm{~W} /(\mathrm{m} \mathrm{K})$ & $\alpha_{a u}$ & 0.115 \\
$\rho c_{v}$ & $2400 \mathrm{~kJ} /\left(\mathrm{K} \mathrm{m}^{3}\right)$ & $\alpha_{E}$ & 0.35 \\
$Q_{\infty}$ & $117,840 \mathrm{~kJ} / \mathrm{m}^{3}$ & $\alpha_{G_{0}}$ & 0.30 \\
$\beta^{\prime}$ & $15 \mu \mathrm{m} /(\mathrm{m} \mathrm{K})$ & $E_{a}$ & $50 \mathrm{~kJ} / \mathrm{mol}$ \\
$\kappa$ & $75 \mu \mathrm{m} / \mathrm{m}$ & $v$ & 0.22 \\
$E_{\infty}$ & $35 \mathrm{GPa}$ & $T_{a}$ & $15^{\circ} \mathrm{C}$ \\
$G_{0 \infty}$ & $25 \mathrm{~N} / \mathrm{m}$ & $A_{T}$ & $0.215 \mathrm{GW} / \mathrm{kg}$ \\
$\mathrm{a}$ & 0.149 & $\mathrm{~b}$ & 0.51 \\
$\mathrm{c}$ & 2.91 & $m$ & 3 \\
\hline
\end{tabular}

6. Bonds should be removed from the calculations if their stretch exceeds the critical value, based on Eq. (27).

7. Calculating the damage level of the nodes by means of Eq. (28).

8. Save the updated displacements, hydration degree and temperature values as the initial values for the next time step.

9. Repeat from the step 3 for the next time step.

\section{Experimental validation of the model}

5.1 Evolution of material strength, heat generation and temperature during the hydration process

To validate the present numerical method, we simulate a concrete cubic sample which is taken from an experimental study $[1,83]$. The dimensions of the cubic sample is $150 \times 150 \times 150 \mathrm{~mm}$. The concrete properties are taken from [1,83] and are given in Table 1 . The testing sample is equipped with thermal sensors located at the top-center of the sample and the whole system is stored in a polystyrene box with a thickness of $50 \mathrm{~mm}$. The chamber temperature is $20{ }^{\circ} \mathrm{C}$ and its humidity is $50 \%$. The initial hydration degree all over the slab is $\alpha_{0}=0.05$. Furthermore, the initial temperature of the concrete slab is $T_{0}=20^{\circ} \mathrm{C}$ and the final temperature is $T_{\infty}=30^{\circ} \mathrm{C}$. The model is discretized uniformly by a grid spacing of $\Delta x=\Delta y=$ $\Delta z=0.075 \mathrm{~m}$ and a total number of 9261 nodes. The incremental time step is taken as $\Delta t=1 \mathrm{~s}$ and the simulation is carried out up to $600 \mathrm{~h}$. The time history of the Young's modulus is represented in Fig. 5. There is an acceptable agreement between the Young's modulus of the three experimental tests $[1,83]$ and that of the peridynamic model.

We also investigate the thermal behaviour of the system. The temperature history is shown in Fig. 6. It can be observed that the maximum temperature reaches up to $38^{\circ} \mathrm{C}$ at the concrete age of $18 \mathrm{~h}$ in the peridynamic model and it is in a remarkable agreement with the experimental measurements $[1,83]$. Furthermore, the accumulated heat generated due to the hydration process in the peridynamic model is compared to the experimental test in Fig. 7. A very good agreement is achieved.

\subsection{Shrinkage phenomenon}

In order to get a deep insight into the chemo-thermomechanical behavior, the shrinkage phenomenon of concrete is examined. Shrinkage is the change of volume of the concrete due to the change of the hydration degree and it is one of the significant aspects of the early-age concrete. The experimental set up (rectangular slabs) is described in $[1,83]$. The dimensions of the slabs are $1000 \times 100 \mathrm{~mm}$ and the related numerical model is solved in a plane strain condition. C20/25 concrete is used in the experimental tests and its properties are taken from [1,83] (see Table 1). The aim of this test is to measure the autogenous shrinkage strain. To this end, the moisture exchange with the ambient medium is prevented. The ambient temperature was measured during the test in $[1,83]$ as depicted in Figure 8 and used into the numerical model to impose a convection boundary 


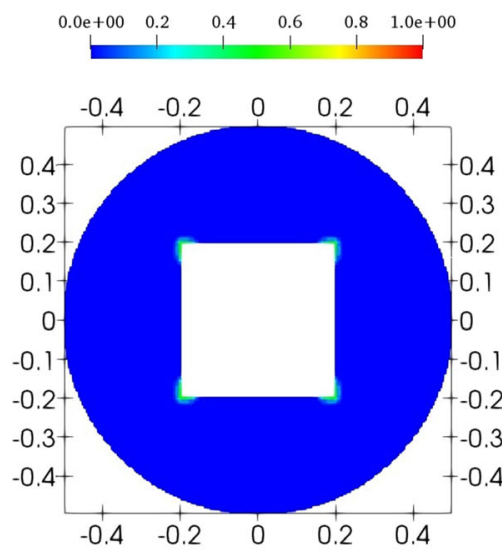

(a) $t=25 \mathrm{~h}$

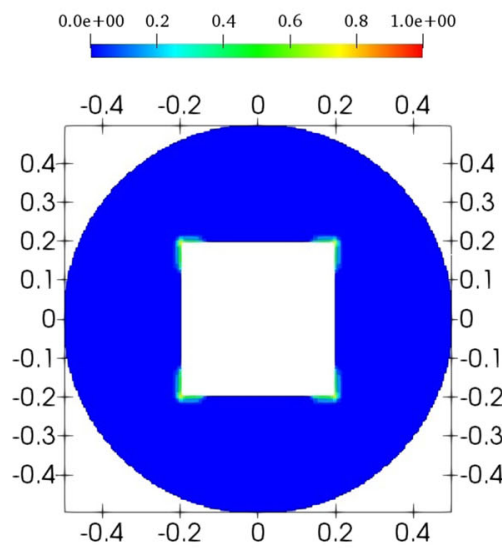

(d) $t=112 \mathrm{~h}$

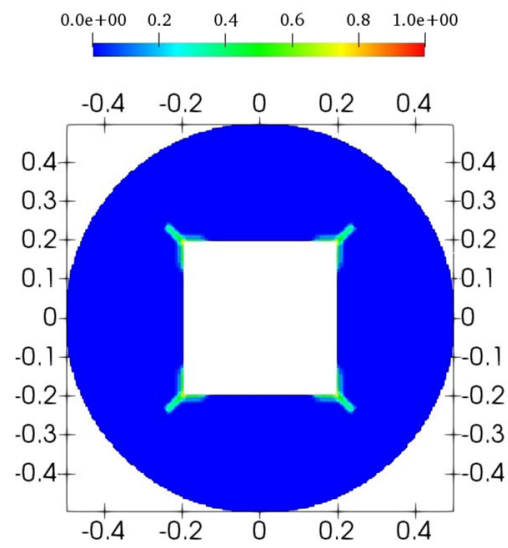

(g) $t=200 \mathrm{~h}$

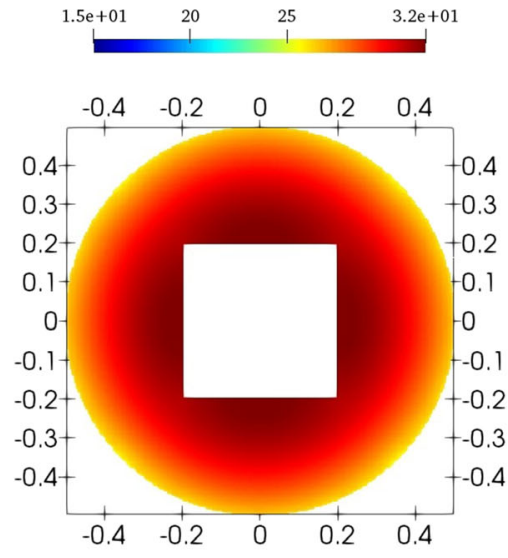

(b) $t=25 \mathrm{~h}$

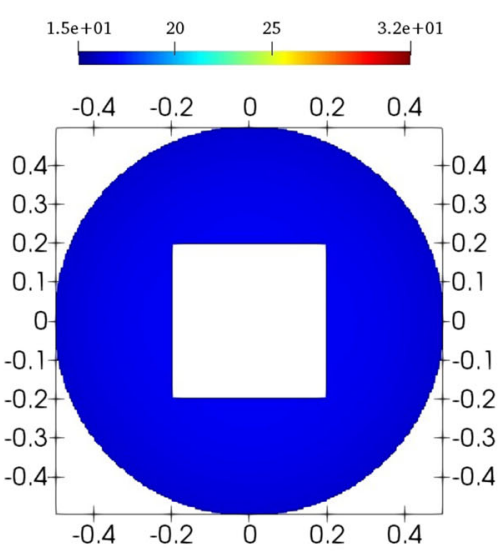

(e) $t=112 \mathrm{~h}$

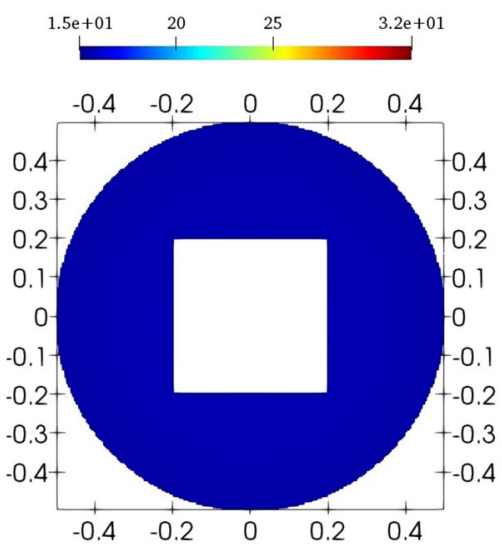

(h) $t=200 \mathrm{~h}$

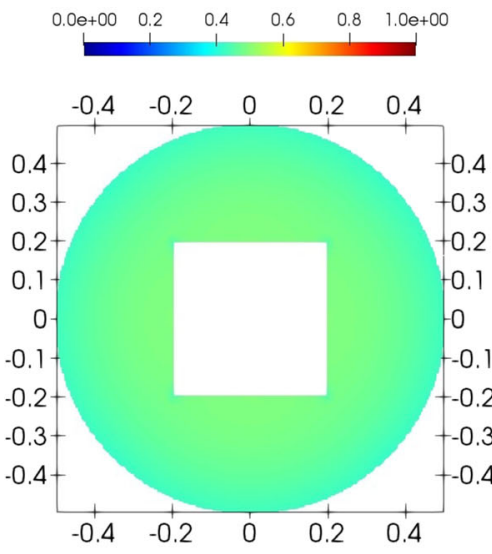

(c) $t=25 \mathrm{~h}$

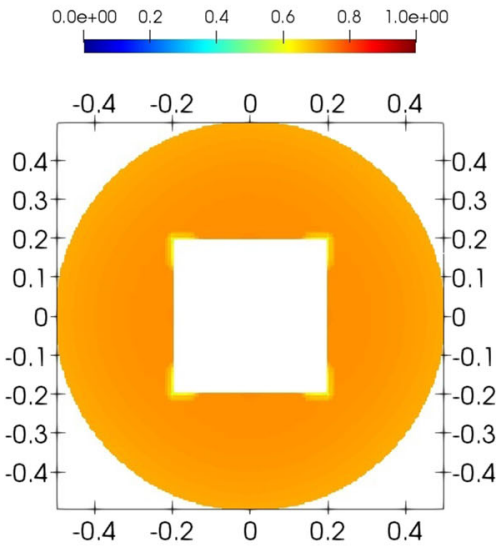

(f) $t=112 \mathrm{~h}$
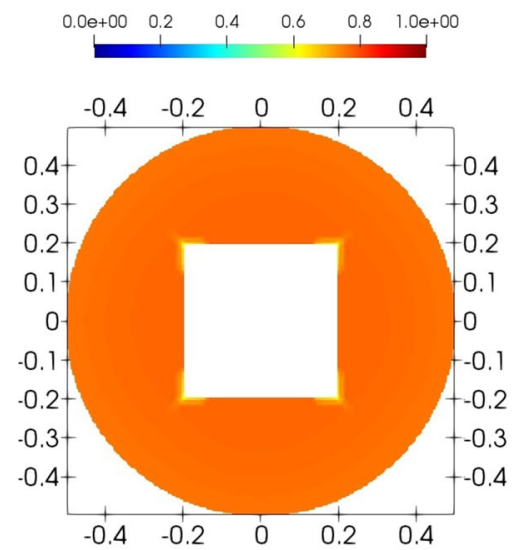

(i) $t=200 \mathrm{~h}$

Fig. 13 Example II: the evolution of the $\mathbf{a}, \mathbf{d}, \mathbf{g}$ damage level $\phi, \mathbf{b}, \mathbf{e}, \mathbf{h}$ temperature $\mathrm{T}\left({ }^{\circ} \mathrm{C}\right)$ and $\mathbf{c}, \mathbf{f}, \mathbf{i}$ hydration degree $\alpha$ during the hydration process using the present approach 

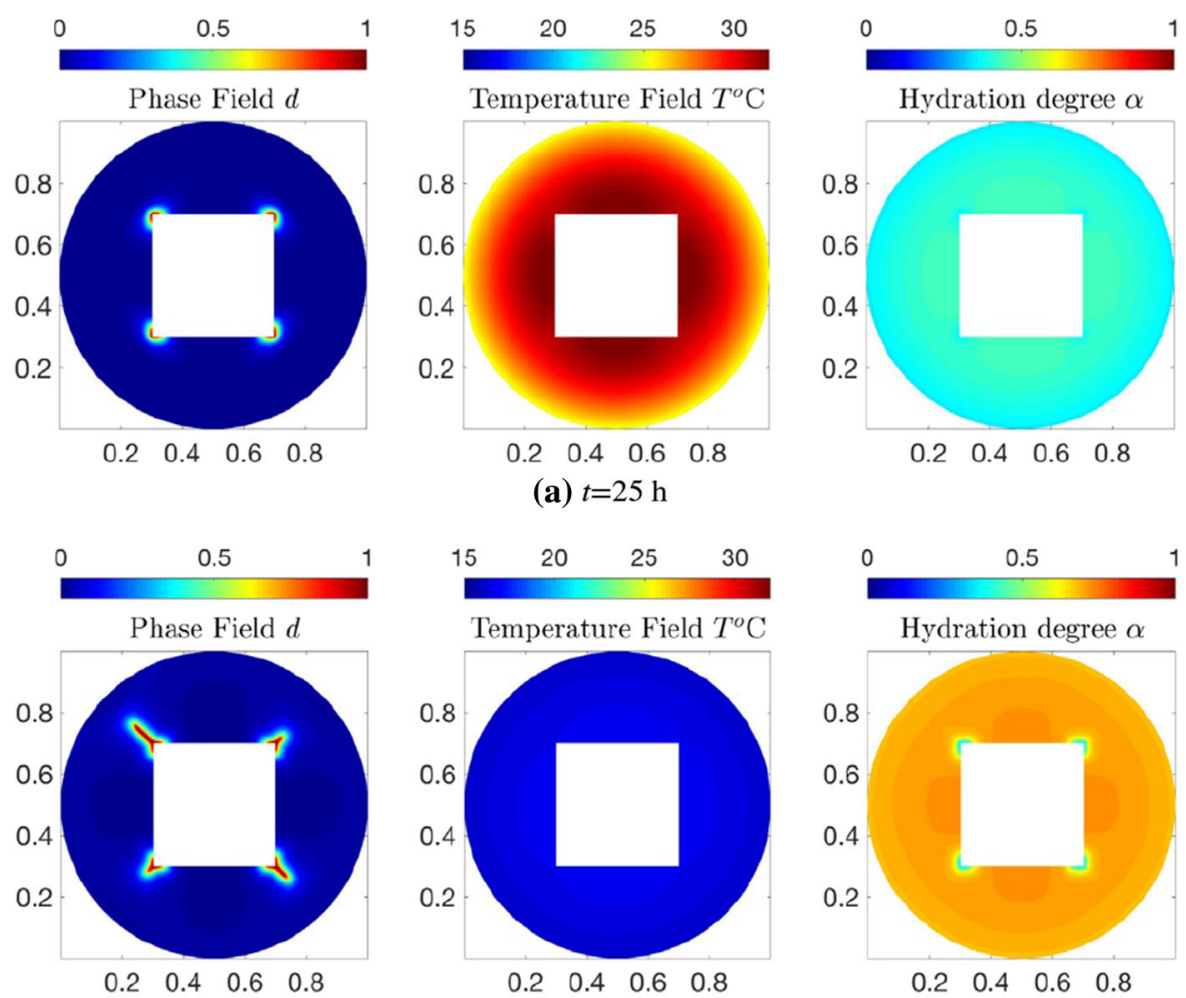

(b) $t=112 \mathrm{~h}$
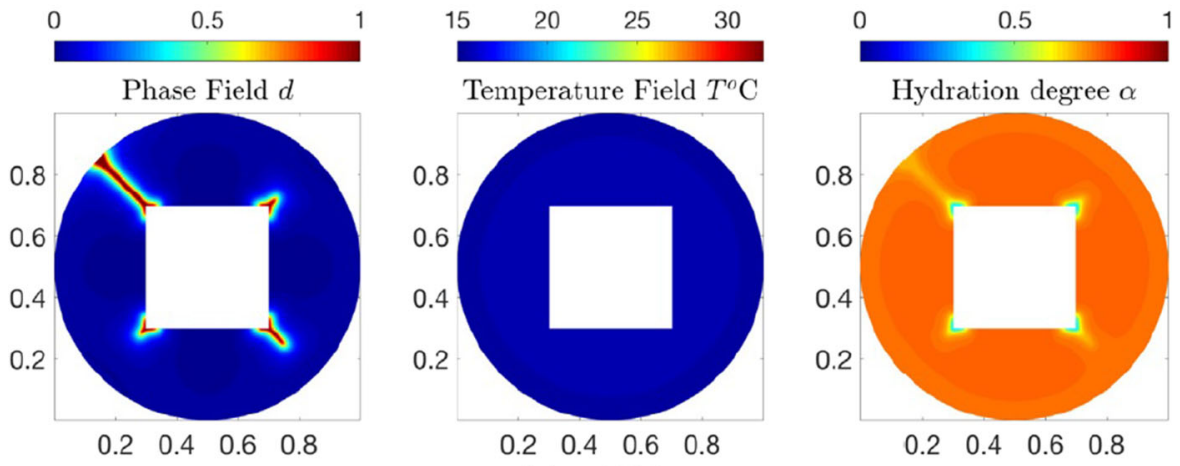

Fig. 14 Example II: the evolution of the phase field $d$, temperature $\mathrm{T}\left({ }^{\circ} \mathrm{C}\right)$ and hydration degree $\alpha$ during the hydration process using the phase field method [29]

condition on all the boundaries $[1,83]$. On the left boundary of the concrete slab, both $x$ and $y$-displacements are fixed, while on all other boundaries both $x$ and $y$-displacements are free. The right side of the slab is in touch with a displacement transducer which records all displacement within a range of $2 \mathrm{~mm}$. The slab is discretized uniformly by a grid spacing of $\Delta x=$ $\Delta y=0.005 \mathrm{~m}$ and a total number of 4221 nodes. The incremental time step is taken as $\Delta t=10 \mathrm{~s}$ and the simulation is carried out up to 28 days. In Fig. 9, the development of shrinkage strain is presented. Using the peridynamic model, the shrinkage strain reaches $-184 \mu \mathrm{m} / \mathrm{m}$ after 28 days which is in a very good agreement with the two experimental tests in [1,83].

Up to here, we presented simple models to investigate the variation of the elastic modules, the evolution of the temperature and the shrinkage strain in early-age concrete. Moreover, we compared them to 


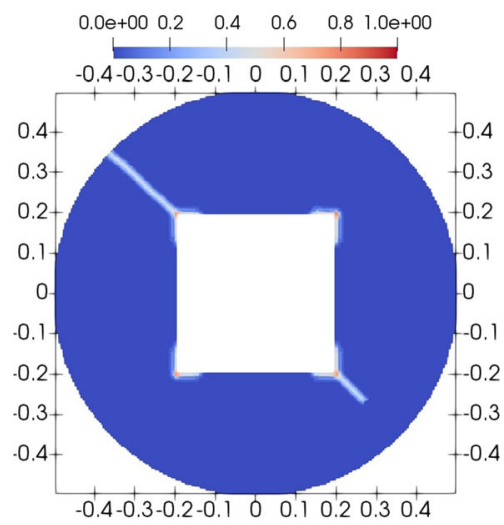

(a)

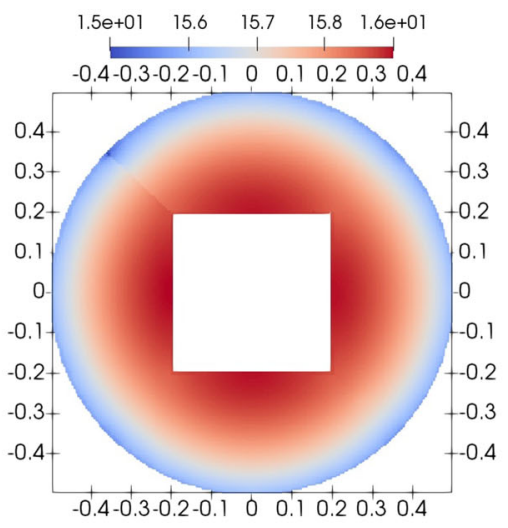

(b)

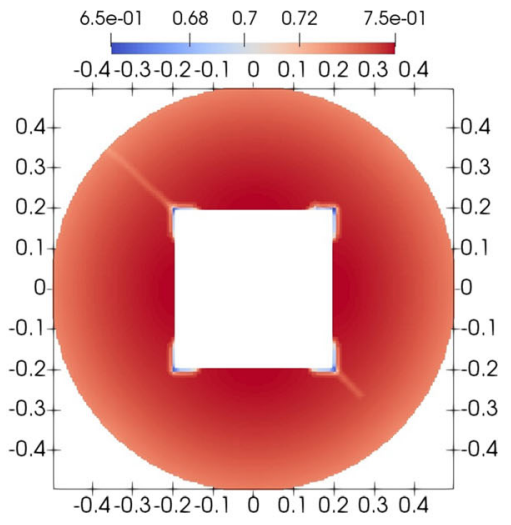

(c)

Fig. 15 Example II: the non-symmetric distribution of the a damage level $\phi$, b temperature $\mathrm{T}\left({ }^{\circ} \mathrm{C}\right)$ and $\mathbf{c}$ hydration degree $\alpha$ after 200 hours using the present approach

the experimental data available in the literature. In the rest of this study, we investigate more complex problems by three other examples.

\section{Numerical examples}

\subsection{Example I: chemo-thermo-mechanical analysis of a concrete slab}

In this example, the temperature variation of a concrete slab, due to the early-age behaviour of concrete, is investigated. Using this example, we aim at validating the fully chemo-thermal reactions via a peridynamic approach. This example has been investigated in $[31,32]$ by using FEM. The authors used two different types of elements known as hybrid and conform, then they compared their results with the experimental data in [84]. Heat transfer occurs across the slab thickness only. This problem is solved in a plane strain condition.

The slab with the dimensions of $1.0 \times 0.35 \mathrm{~m}$ is considered here (see Fig. 10.) Two thermal sensors, A and $\mathrm{B}$, are placed at $0.05 \mathrm{~m}$ from the bottom and the top surfaces respectively. The same material parameters used in [29, 31] are assumed to solve this example. These parameters are given in Table 2. The convective boundary conditions have coefficients $h_{c}=7.5 \mathrm{~W} /\left(\mathrm{m}^{2} \mathrm{~K}\right)$ (convection with air) and $h_{c}=$
$4.5 \mathrm{~W} /\left(\mathrm{m}^{2} \mathrm{~K}\right)$ (convection with soil) at the bottom-end (P1-P2) and the top-end (P3-P4) respectively. The environment air temperature represented in Fig. 11 is changing during the simulation. The initial hydration degree all over the slab is $\alpha_{0}=0.05$. Furthermore, the initial temperature of the concrete slab and the surface of the supporting soil is $T_{0}=17.5^{\circ} \mathrm{C}$ and $T_{0 \text { Soil }}=$ $17{ }^{\circ} \mathrm{C}$ respectively. The isolated boundary condition is applied to the right (P2-P3) and the left (P1-P4) sides of the slab (see Fig. 10). Furthermore, the $x$-displacements are fixed in the left and the right sides of the slab while $y$-displacements are free [29, 31]. On the bottom-end (P1-P2), $y$-displacements are fixed, while the $x$-displacements are free $[29,31]$. On the top side of the slab (P3-P4), both $x$ and $y$-displacements are free. The slab is discretized uniformly by a grid spacing of $\Delta x=\Delta y=0.05 \mathrm{~m}$ and a total number of 14,271 nodes. The incremental time step is taken as $\Delta t=10 \mathrm{~s}$. Two nodes $\mathbf{x}_{A}=(0.5,0.05) \mathrm{m}$ and $\mathbf{x}_{B}=$ $(0.5,0.3) \mathrm{m}$ are chosen to investigate the time history of the temperature. The time history of the temperature for nodes $\mathbf{x}_{A}$ and $\mathbf{x}_{B}$ are shown in Fig. 11. The results for both of the nodes are in an acceptable agreement with the FEM models (conform and hybrid) in $[31,32]$. Moreover, the peridynamic temperature time history is in a good agreement with the measured data in [84]. 
Fig. 16 Example II: time history of a temperature $\mathrm{T}$ $\left({ }^{\circ} \mathrm{C}\right)$ and $\mathbf{b}$ hydration degree $\alpha$ of node $\mathbf{x}_{A}$ and node $\mathbf{x}_{B}$

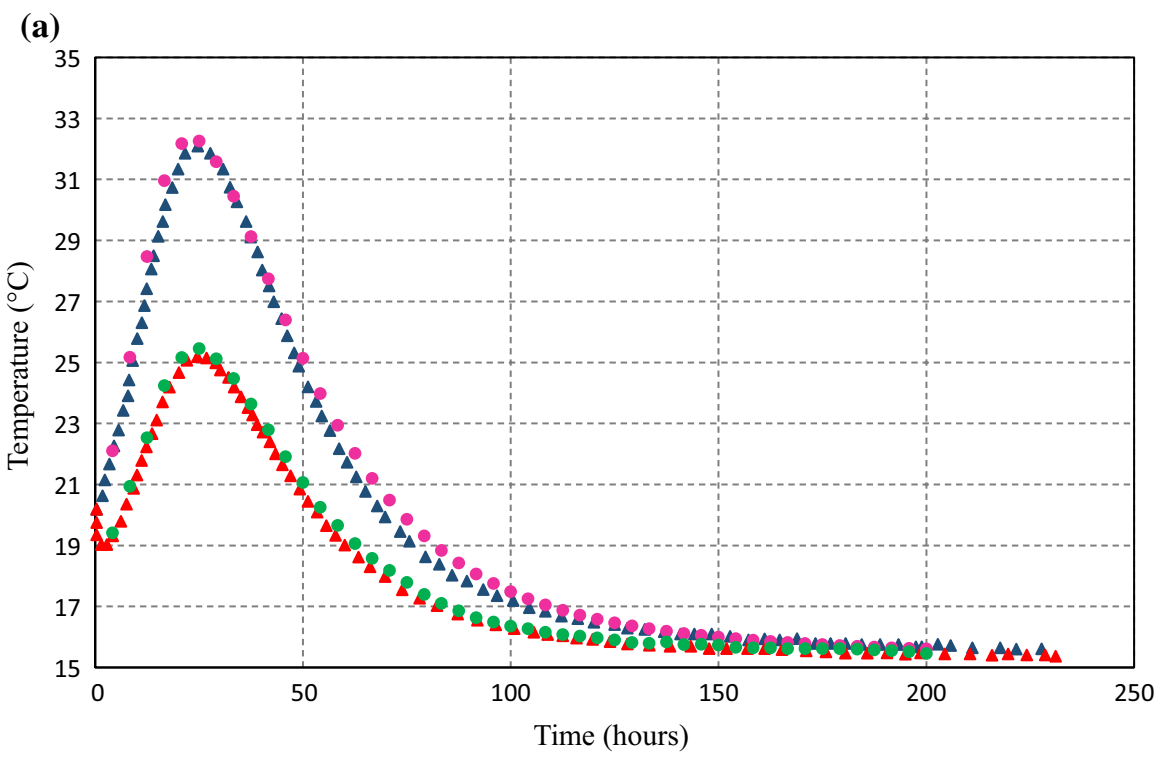

$\Delta$ Phase field node $\mathrm{A} \Delta$ P Phase field node B $\quad$ Peridynamic node A Peridynamic node B

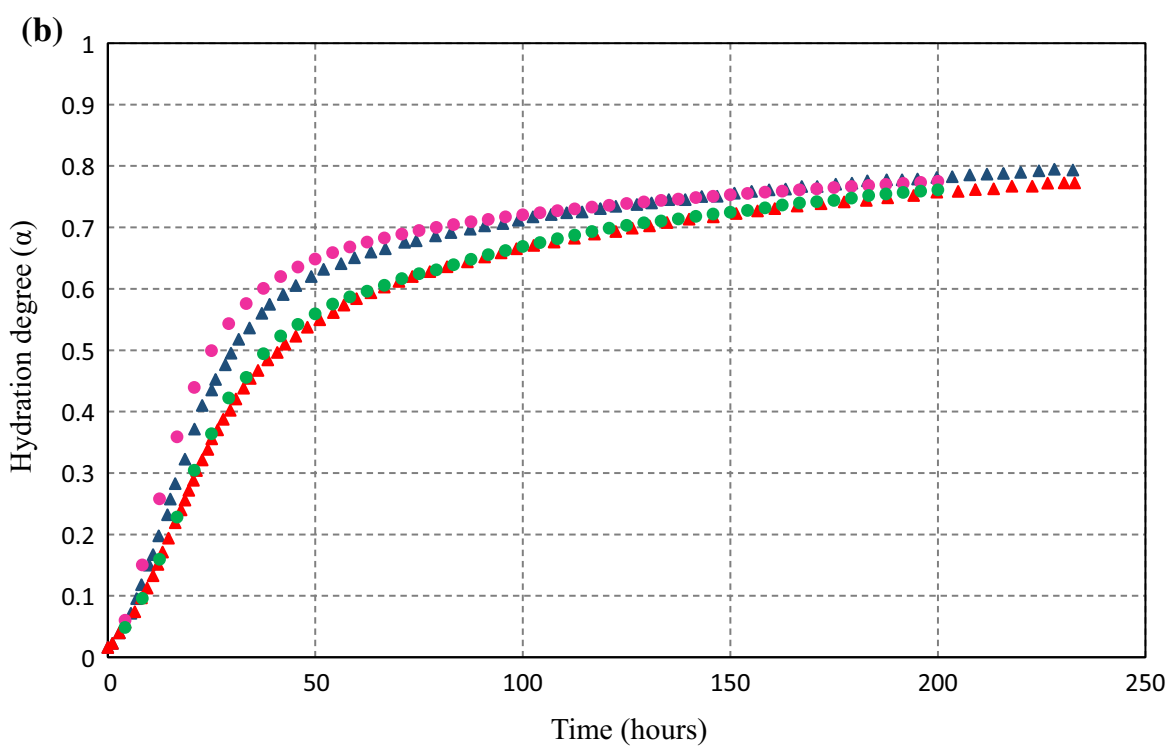

$\Delta$ Phase field node A $\triangle$ Phase field node B - Peridynamic node A Peridynamic node B
6.2 Example II: hydration reaction in a cement ring structure

In this example, we investigate the chemo-thermomechanical crack propagation in a homogeneous circular concrete specimen. A square hole is considered at the centre of this specimen as shown in Fig. 12. This example has been solved in [29] using the phase field method. The material parameters in [29] are considered in this example and are listed in Table 3. The radius of the circular specimen and the size of the square hole are taken as $r=0.5 \mathrm{~m}$ and 

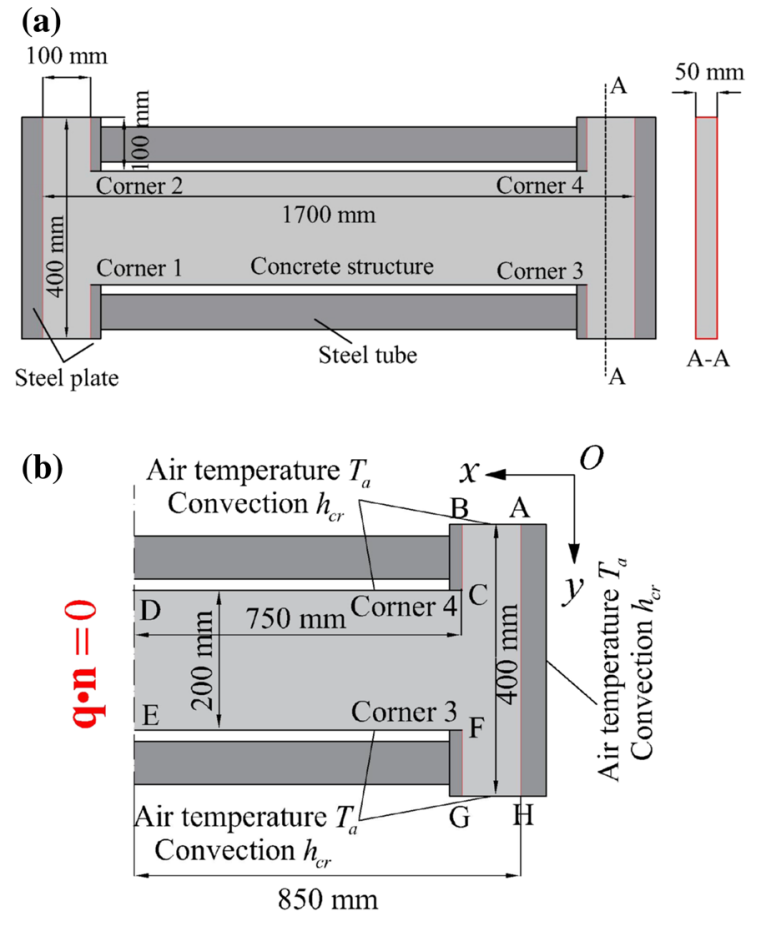

Fig. 17 Example III: geometry and the boundary conditions $\mathbf{a}$ description of the experimental specimen $\mathbf{b}$ the model used for the simulation

Table 4 Example III material properties of the AISI 4130 Alloy Steel (Ref. [1])

\begin{tabular}{llll}
\hline Parameter & Value & Parameter & Value \\
\hline$k_{s}$ & $42.7 \mathrm{~W} /(\mathrm{m} \mathrm{K})$ & $E_{s}$ & $200 \mathrm{GPa}$ \\
$\rho c_{s}$ & $3744 \mathrm{~kJ} /\left(\mathrm{K} \mathrm{m}^{3}\right)$ & $v_{s}$ & 0.3 \\
$\beta_{s}^{\prime}$ & $124,014 \mathrm{~kJ} / \mathrm{m}^{3}$ & $h_{c r}$ & $8 \mathrm{~W} /\left(\mathrm{m}^{2} \mathrm{~K}\right)$ \\
\hline
\end{tabular}

$a=0.4 \mathrm{~m}$, respectively. The initial conditions $T_{0}=$ $20^{\circ} \mathrm{C}$ and $\alpha_{0}=0.01$ are taken for the whole specimen. A convection boundary condition with the convection coefficient of $h=8 \mathrm{~W} /\left(\mathrm{m}^{2} \mathrm{~K}\right)$ is applied over the system as shown in Fig. 12. The ambient temperature is assumed to be constant during the whole interaction process and is taken as $T_{a}=15^{\circ} \mathrm{C}$. To impose the mechanical boundary conditions, the left and the right sides of the square hole are fixed along the $x$-direction while the $y$-displacements are free. Moreover, the top and the bottom edges of the square hole are fixed along the $y$-direction while the $x$-displacements are free.
The slab is discretized uniformly by a grid spacing of $\Delta x=\Delta y=0.005 \mathrm{~m}$ and a total number of 25156 nodes. The incremental time step is taken as $\Delta t=10 \mathrm{~s}$ for a total of 72000 steps. The contour plots of the damage, temperature field and hydration degree for three different time steps are depicted in Figure 13. The comparison of Fig. 13, with the phase field results taken from [29] in Fig. 14, shows that there is an acceptable agreement between the peridynamic and phase field approaches. As shown in Figure 13g, the damage evolution in the peridynamic model is absolutely symmetric which shows there is significantly low round-off error in our simulations. The comparison of Figs. 13 and 14 is apparently not very good, because the phase field model crack evolves earlier and completely breaks the sample, while the peridynamic model shows smaller damage values. However, if we impose a very small perturbation in the damage value of only one node we obtain damage evolution contour plots after 200 hours in Fig. 15a similar to the phase field results in Fig. 14. Since the model has a symmetrical geometry and we apply symmetric loads and constrains the numerical results must be symmetric; however, in some numerical codes due to the cumbersome computations a round-off error occurs in the computations which could lead to non-symmetric results. For further validation of the present method, two nodes $\mathbf{x}_{A}=(0.2,0) \mathrm{m}$ and $\mathbf{x}_{B}=(0.5,0) \mathrm{m}$ see (Fig. 12) are chosen to investigate the time history of the temperature and hydration degree. The time history of the temperature and hydration degree for nodes $\mathbf{x}_{A}$ and $\mathbf{x}_{B}$ are shown in Figs. 16a, b respectively. The results for both of the nodes are in an acceptable agreement with the phase field models in [29].

\subsection{Example III: comparison of the crack shape in a concrete beam}

In this example, crack initiation and propagation in a non-reinforced concrete C20/25 beam is investigated by using the proposed peridynamic model. The results will be compared to the experimental tests and the phase field model simulation results [1]. As mentioned in [1], C20/25 is risky for the durability of the structures and it is prone to loss of performance due to cracking induced by early-age hydration. Damage and fracture may take place in a critical working condition as mentioned in [1]. Figure 17 shows the geometry 


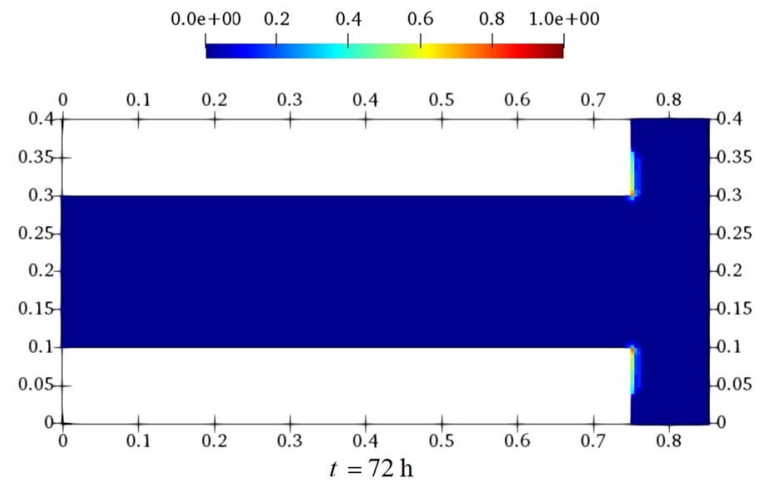

(a)

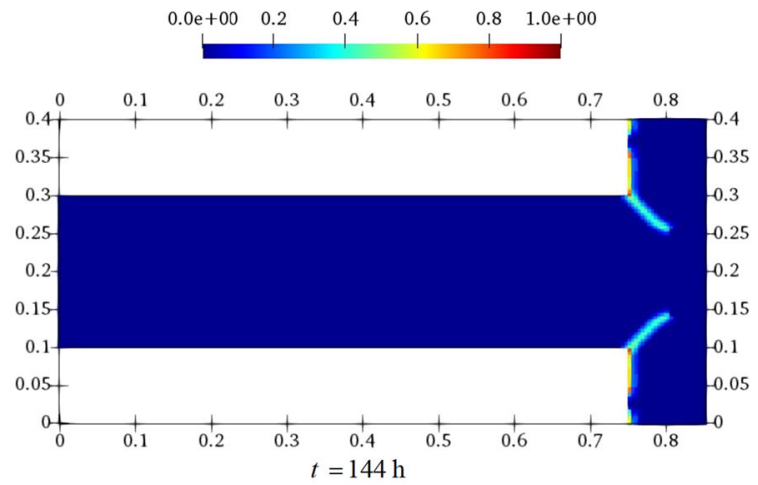

(c)

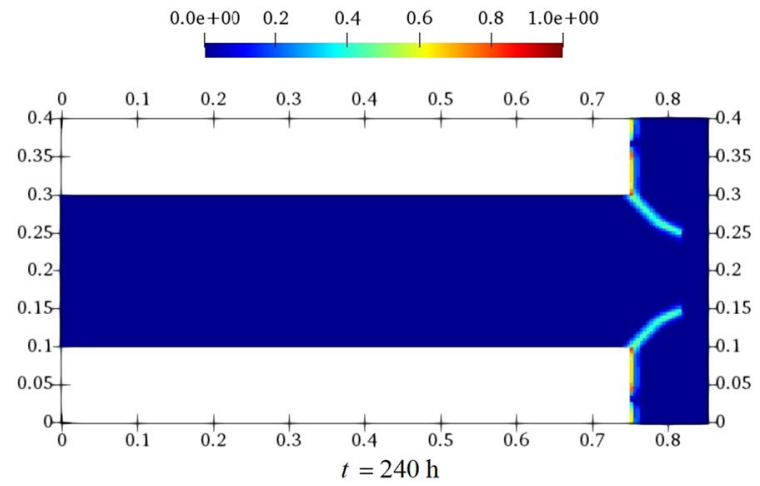

(e)

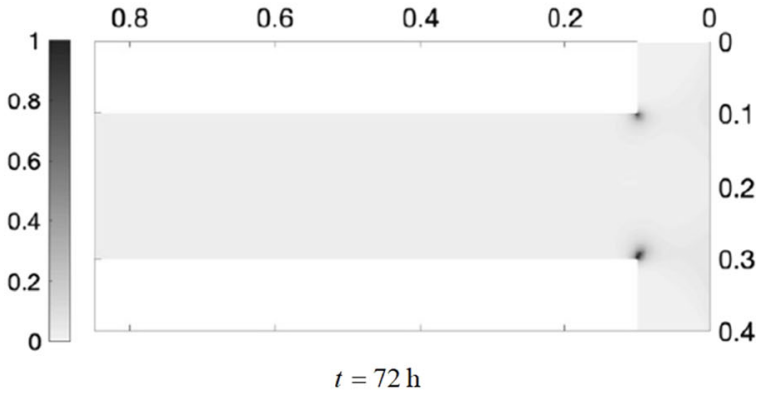

(b)

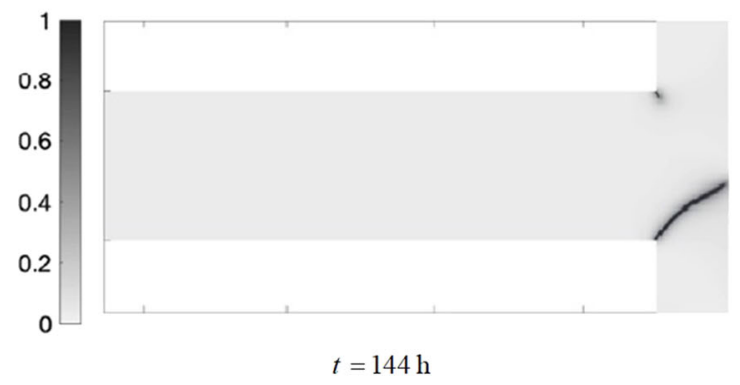

(d)

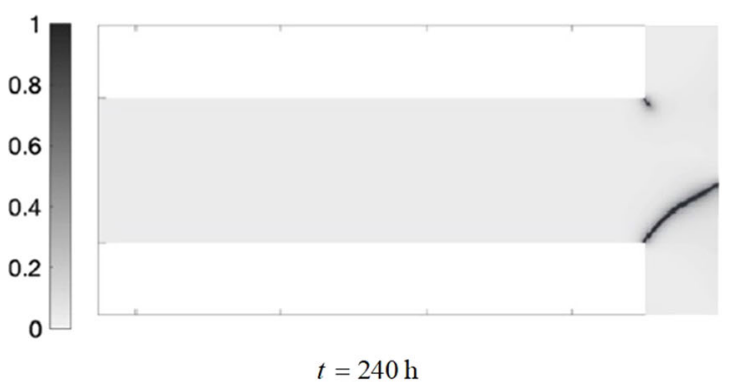

(f)

Fig. 18 Example III: the symmetric evolution of the a, c, e damage level, using the present approach, $\mathbf{b}, \mathbf{d}, \mathbf{f}$ the phase field model [1]

and the boundary conditions of the specimen. The central part of the H-shape specimen is bracing, while stiff steel tubes are arranged parallel and symmetrically to the long sides of the middle part. Four critical zones with a high risk of cracking emerges at four corners of the specimen as depicted in Fig. 17a. The material parameters in [1] are considered in this example and listed in Table 1. The initial temperature is assumed to be $20^{\circ} \mathrm{C}$ [1]. For the sake of simplicity, only half of the specimen is modelled in our simulations due to its symmetric shape. The steel tubes and plates are made of AISI 4130 Alloy steel; its properties are taken from Nguyen et al. [1] and are listed in 


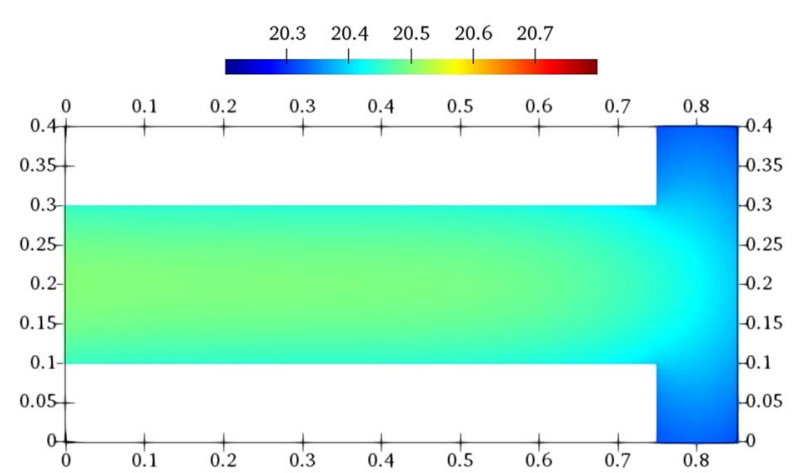

(a)

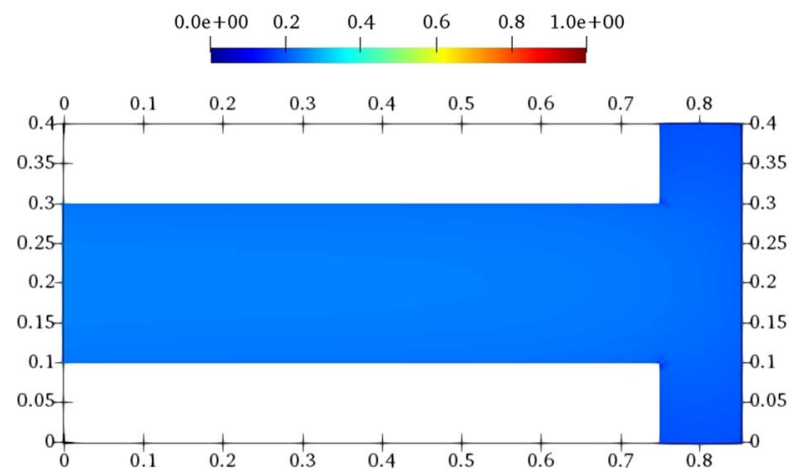

(c)

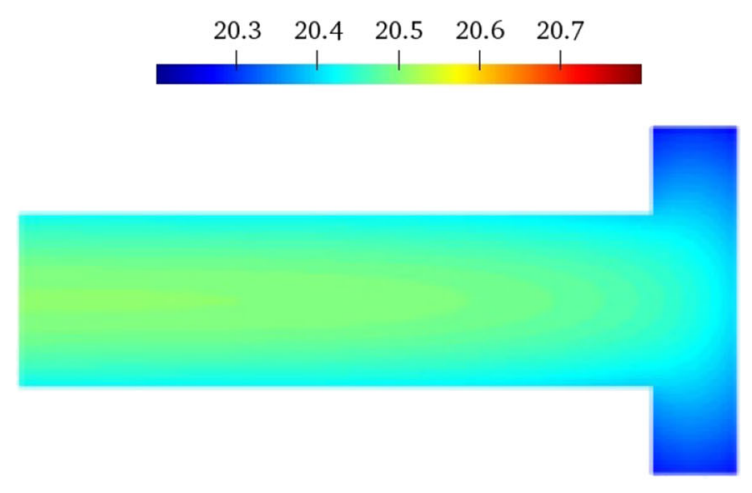

(b)

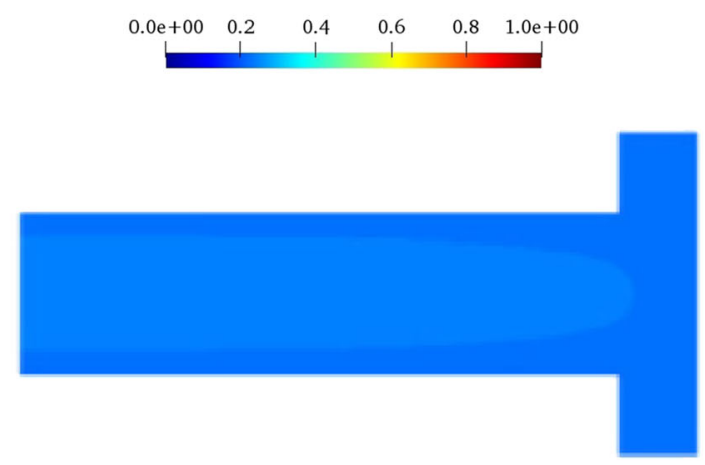

(d)

Fig. 19 Example III: the distribution of the temperature $\mathrm{T}\left({ }^{\circ} \mathrm{C}\right) \mathbf{a}$ using the present approach $\mathbf{b}$ using the phase field approach [1] and hydration degree $\alpha \mathbf{c}$ using the present approach $\mathbf{d}$ using the phase field approach [1] after $24 \mathrm{~h}$

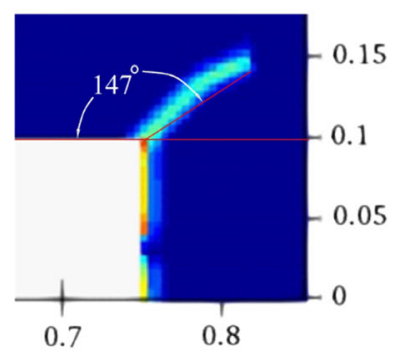

(a)

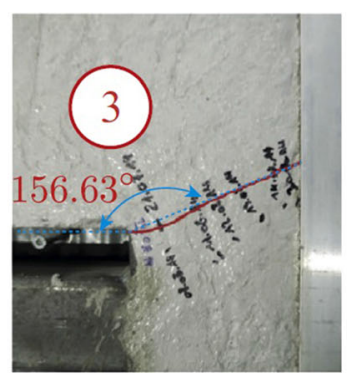

(b)

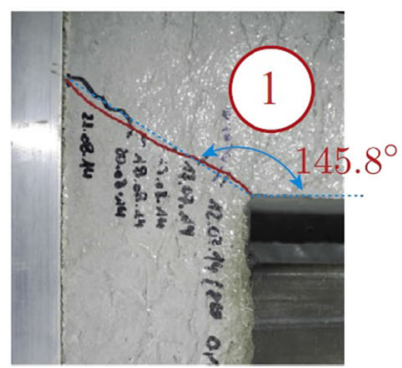

(c)

Fig. 20 Crack morphology obtained by a present approach $\mathbf{b}$ and $\mathbf{c}$ experiment in [1]

Table 4. The following assumptions are considered for the boundary conditions (see Ref. [1]):

1. In the edges $\mathrm{AB}, \mathrm{CD}, \mathrm{EF}$ and $\mathrm{HG}$, which are in contact with the air environment, convective boundary conditions with a convection coefficient of $h_{c r}=8 \mathrm{~W} /\left(\mathrm{m}^{2} \mathrm{~K}\right)$, and air temperature of $T_{a}=$ $20^{\circ} \mathrm{C}$ are used.
2. For the concrete interfaces in contact with the steel tubes and plates, thermal conductance conditions are applied with a conductance coefficient of $h_{c d}=10^{4} \mathrm{~W} /\left(\mathrm{m}^{2} \mathrm{~K}\right)$, then the convective boundary conditions are applied to the steel-air surfaces.

3. For the mechanical boundary conditions, the displacements along the $x$-direction at the symmetrical edge of both concrete beam (DE) and the 
steel tube are zero, while their $y$-displacements are free. It is assumed that there is a perfect cohesion between the concrete and the steel interfaces so that the displacements along $x$-directions at both surfaces BC and FG are fixed while their $y$ displacements are free. In all other boundaries $(\mathrm{AB}, \mathrm{CD}, \mathrm{FE}, \mathrm{GH})$, both $x$ and $y$-displacements are free.

4. The initial conditions $T_{0}=20^{\circ} \mathrm{C}$ and $\alpha_{0}=0.01$ are taken for the whole structure.

The slab is discretized uniformly by a grid spacing of $\Delta x=\Delta y=0.00425 \mathrm{~m}$ and a total number of 10599 nodes. The incremental time step is taken as $\Delta t=10 \mathrm{~s}$ for a total of 86400 steps. The contour plots of the damage are depicted in Fig. 18 for three different time steps.

The comparison of the crack paths in Fig. 18a, c, e, and the results obtained by the phase field model in Fig. 18b, d, f, shows that there is a very good agreement between the peridynamic and phase field approaches. Moreover, the temperature field and hydration degree at time $t=240$ hours are represented in Fig. 19.

The comparison of Fig. 19a, c, and the temperature field and hydration degree contour-plots obtained by the phase field model in Fig. 19b, d, indicates that there is an acceptable agreement between the peridynamic and phase field approaches. In order to compare the crack paths quantitatively, one may analyse the crack angles as shown in Fig. 20. This angle for the experimental test [1] is $145.8^{\circ}$ and $156.63^{\circ}$ at corner 1 and 3 respectively (see Fig. 20). This angle in the present study is absolutely symmetric and is equal to $147^{\circ}$ (see Fig. 20). The crack angle obtained using the proposed approach is in a good agreement with the experimental test.

\section{Conclusions}

In this paper, a new technique is developed in a peridynamic framework to investigate the complex fracture mechanism induced by the chemo-thermomechanical reactions at early ages in a cement based structure. Using this method, one is able to predict complex crack patterns without any a priori hypothesis on crack onset and geometry. The accuracy of the model is examined through problems such as chemo- thermo-mechanical analysis of a concrete slab, hydration reaction in a cement ring structure and crack propagation over a concrete beam. Hydration degree, temperature and crack paths are compared to the experimental data and to numerical solutions produced by the FEM, hybrid FEM and phase field methods. A proper agreement is achieved between all sets of results. The new computational method is capable of producing symmetric results. More importantly, the crack angle observed by the present method is in a good agreement with the experimental data.

Acknowledgements Authors acknowledge the support they received from MIUR under the research project PRIN2017DEVISU and from University of Padua under the research projects BIRD2018 NR.183703/18 and BIRD2017 NR.175705/ 17.

Funding Open access funding provided by Politecnico di Milano within the CRUI-CARE Agreement.

Open Access This article is licensed under a Creative Commons Attribution 4.0 International License, which permits use, sharing, adaptation, distribution and reproduction in any medium or format, as long as you give appropriate credit to the original author(s) and the source, provide a link to the Creative Commons licence, and indicate if changes were made. The images or other third party material in this article are included in the article's Creative Commons licence, unless indicated otherwise in a credit line to the material. If material is not included in the article's Creative Commons licence and your intended use is not permitted by statutory regulation or exceeds the permitted use, you will need to obtain permission directly from the copyright holder. To view a copy of this licence, visit http://creativecommons.org/licenses/by/4.0/.

\section{References}

1. Nguyen T-T, Weiler M, Waldmann D (2019) Experimental and numerical analysis of early age behavior in non-reinforced concrete. Constr Build Mater 210:499-513

2. Bentz DP (2008) A review of early-age properties of cement-based materials. Cement Concrete Res 38(2):196-204

3. Bernard O, Ulm F-J, Lemarchand E (2003) A multiscale micromechanics-hydration model for the early-age elastic properties of cement-based materials. Cement Concrete Res 33(9):1293-1309

4. Boumiz A, Vernet C, Tenoudji FC (1996) Mechanical properties of cement pastes and mortars at early ages: evolution with time and degree of hydration. Adv Cement Based Mater 3(3-4):94-106 
5. Kolver K, Igarashi S, Bentur A (1999) Tensile creep behavior of high strength concretes at early ages. Matér. Struct. 32(5):383-387

6. Østergaard L, Lange DA, Altoubat SA, Stang H (2001) Tensile basic creep of early-age concrete under constant load. Cement Concrete Res 31(12):1895-1899

7. Kovler K (1994) Testing system for determining the mechanical behaviour of early age concrete under restrained and free uniaxial shrinkage. Mater Struct 27(6):324

8. Lura P, van Breugel K, Maruyama I (2001) Effect of curing temperature and type of cement on early-age shrinkage of high-performance concrete. Cement Concrete Res 31(12):1867-1872

9. Cusson D, Hoogeveen T (2008) Internal curing of highperformance concrete with pre-soaked fine lightweight aggregate for prevention of autogenous shrinkage cracking. Cement Concrete Res 38(6):757-765

10. Darquennes A, Staquet S, Delplancke-Ogletree M-P, Espion B (2011) Effect of autogenous deformation on the cracking risk of slag cement concretes. Cement Concrete Compos 33(3):368-379

11. Shen D, Jiang J, Shen J, Yao P, Jiang G (2016) Influence of curing temperature on autogenous shrinkage and cracking resistance of high-performance concrete at an early age. Constr Build Mater 103:67-76

12. Wan L, Wendner R, Liang B, Cusatis G (2016) Analysis of the behavior of ultra high performance concrete at early age. Cement Concrete Compos 74:120-135

13. Wan L, Wendner R, Cusatis G, Behavior of ultra-highperformance concrete at early age: experiments and simulations. In: 1st international interactive symposium on UHPC

14. Shi N, Ouyang J, Zhang R, Huang D (2014) Experimental study on early-age crack of mass concrete under the controlled temperature history. Adv Mater Sci Eng 2014

15. Chu I, Kwon SH, Amin MN, Kim J-K (2012) Estimation of temperature effects on autogenous shrinkage of concrete by a new prediction model. Constr Build Mater 35:171-182

16. Briffaut M, Benboudjema F, Torrenti J-M, Nahas G (2012) Concrete early age basic creep: experiments and test of rheological modelling approaches. Constr Build Mater 36:373-380

17. Raoufi K, Schlitter J, Bentz D, Weiss J (2011) Parametric assessment of stress development and cracking in internally cured restrained mortars experiencing autogenous deformations and thermal loading. Adv Civil Eng 2011

18. Briffaut M (2010) Study of the early age cracking of concrete massive structures: effect of the temperature decrease rate, steelreinforcement and construction joints (No. FRNCTH-8212). Ecole Normale Superieure de Cachan 44(30):202

19. Cusson D, Hoogeveen T (2007) An experimental approach for the analysis of early-age behaviour of high-performance concrete structures under restrained shrinkage. Cement Concrete Res 37(2):200-209

20. Cervera M, Oliver J, Prato T (1999) Thermo-chemo-mechanical model for concrete. i: Hydration and aging. J Eng Mech 125(9):1018-1027

21. De Schutter G (1999) Degree of hydration based kelvin model for the basic creep of early age concrete. Mater Struct 32(4):260
22. Bazant ZP (1988) Mathematical modeling of creep and shrinkage of concrete. Wiley

23. Ulm F-J, Coussy O (1995) Modeling of thermochemomechanical couplings of concrete at early ages. J Eng Mech 121(7):785-794

24. De Schutter G (2002) Finite element simulation of thermal cracking in massive hardening concrete elements using degree of hydration based material laws. Comput Struct 80(27):2035-2042

25. De Borst R, Van den Boogaard A (1994) Finite-element modeling of deformation and cracking in early-age concrete. J Eng Mech 120(12):2519-2534

26. Bažant ZP, Kim J-K, Jeon S-E (2003) Cohesive fracturing and stresses caused by hydration heat in massive concrete wall. J Eng Mech 129(1):21-30

27. Lee Y, Kim J-K (2009) Numerical analysis of the early age behavior of concrete structures with a hydration based microplane model. Comput Struct 87(17-18):1085-1101

28. Grassl P, Wong HS, Buenfeld NR (2010) Influence of aggregate size and volume fraction on shrinkage induced micro-cracking of concrete and mortar. Cement Concrete Res 40(1):85-93

29. Nguyen T-T, Waldmann D, Bui TQ (2019) Computational chemo-thermo-mechanical coupling phase-field model for complex fracture induced by early-age shrinkage and hydration heat in cement-based materials. Comput Methods Appl Mech Eng 348:1-28

30. Benboudjema F, Torrenti J-M (2008) Early-age behaviour of concrete nuclear containments. Nucl Eng Des 238(10):2495-2506

31. Faria R, Azenha M, Figueiras JA (2006) Modelling of concrete at early ages: application to an externally restrained slab. Cement Concrete Compos 28(6):572-585

32. Teixeira de Freitas JA, Cuong PT, Faria R, Azenha M (2013) Modelling of cement hydration in concrete structures with hybrid finite elements. Finite Elem Anal Des 77:16-30

33. Briffaut M, Benboudjema F, Torrenti JM, Nahas G (2011) Numerical analysis of the thermal active restrained shrinkage ring test to study the early age behavior of massive concrete structures. Eng Struct 33(4):1390-1401

34. Roy P, Pathrikar A, Deepu S, Roy D (2017) Peridynamics damage model through phase field theory. Int J Mech Sci 128:181-193

35. Silling SA (2000) Reformulation of elasticity theory for discontinuities and long-range forces. J Mech Phys Solids 48(1):175-209

36. Silling SA, Askari E (2005) A meshfree method based on the peridynamic model of solid mechanics. Comput Struct 83(17):1526-1535

37. Silling SA, Epton M, Weckner O, Xu J, Askari E (2007) Peridynamic states and constitutive modeling. J Elast 88(2):151-184

38. Wang Y-T, Zhou X-P, Kou M-M (2019) Three-dimensional numerical study on the failure characteristics of intermittent fissures under compressive-shear loads. Acta Geotech 14(4):1161-1193

39. Bazazzadeh S, Zaccariotto M, Galvanetto U (2019) Fatigue degradation strategies to simulate crack propagation usingperidynamic based computational methods. Latin Am J Solids Struct 16:e163 
40. Zaccariotto M, Sarego G, Dipasquale D, Shojaei A, Bazazzadeh S, Mudric T, Duzzi M, Galvanetto U (2017) Discontinuous mechanical problems studied with a peridynamics-based approach. Aerotec Missili Spazio 96(1):44-55

41. Ongaro G, Seleson P, Galvanetto U, Ni T, Zaccariotto M (2021) Overall equilibrium in the coupling of peridynamics and classical continuum mechanics. Comput Methods Appl Mech Eng 381:113515

42. Alebrahim R, Packo P, Zaccariotto M, Galvanetto U (2021) Wave propagation improvement in two-dimensional bondbased peridynamics model. Proc Inst Mech Eng, Part C: J Mech Eng Sci. https://doi.org/10.1177/0954406220985551

43. Gerstle W, Sau N, Silling S (2007) Peridynamic modeling of concrete structures. Nucl Eng Des 237(12):1250-1258

44. Bobaru F, Duangpanya M (2010) The peridynamic formulation for transient heat conduction. Int J Heat Mass Transf 53(19):4047-4059

45. Bobaru F, Duangpanya M (2012) A peridynamic formulation for transient heat conduction in bodies with evolving discontinuities. J Comput Phys 231(7):2764-2785

46. Oterkus S, Madenci E, Agwai A (2014) Peridynamic thermal diffusion. J Comput Phys 265:71-96

47. Bazazzadeh S, Mossaiby F, Shojaei A (2020) An adaptive thermo-mechanical peridynamic model for fracture analysis in ceramics. Eng Fract Mech 223:106708

48. Oterkus S, Madenci E, Agwai A (2014) Fully coupled peridynamic thermomechanics. J Mech Phys Solids 64:1-23

49. Oterkus S, Madenci E (2017) Peridynamic modeling of fuel pellet cracking. Eng Fract Mech 176:23-37

50. D'Antuono P, Morandini M (2017) Thermal shock response via weakly coupled peridynamic thermo-mechanics. Int $\mathbf{J}$ Solids Struct 129:74-89

51. Wang Y, Zhou X, Kou M (2018) A coupled thermo-mechanical bond-based peridynamics for simulating thermal cracking in rocks. Int J Fract 211(1):13-42

52. Wang Y, Zhou X, Kou M (2018) Peridynamic investigation on thermal fracturing behavior of ceramic nuclear fuel pellets under power cycles. Ceram Int 44(10):11512-11542

53. Shojaei A, Mossaiby F, Zaccariotto M, Galvanetto U (2018) An adaptive multi-grid peridynamic method for dynamic fracture analysis. Int J Mech Sci 144:600-617

54. Ren H, Zhuang X, Rabczuk T (2017) Dual-horizon peridynamics: A stable solution to varying horizons. Comput Methods Appl Mech Eng 318:762-782

55. Gu X, Zhang Q, Xia X (2017) Voronoi-based peridynamics and cracking analysis with adaptive refinement. Int J Numer Methods Eng 112(13):2087-2109

56. Xu Z, Zhang G, Chen Z, Bobaru F (2018) Elastic vortices and thermally-driven cracks in brittle materials with peridynamics. Int J Fract 209(1):203-222

57. Mossaiby F, Shojaei A, Zaccariotto M, Galvanetto U (2017) OpenCL implementation of a high performance 3D peridynamic model on graphics accelerators. Comput Math Appl 74(8):1856-1870

58. Zaccariotto M, Mudric T, Tomasi D, Shojaei A, Galvanetto U (2018) Coupling of FEM meshes with peridynamic grids. Comput Methods Appl Mech Eng 330:471-497
59. Shojaei A, Mudric T, Zaccariotto M, Galvanetto U (2016) A coupled meshless finite point/peridynamic method for $2 \mathrm{~d}$ dynamic fracture analysis. Int J Mech Sci 119:419-431

60. Seleson P, Beneddine S, Prudhomme S (2013) A forcebased coupling scheme for peridynamics and classical elasticity. Comput Mater Sci 66:34-49

61. Chen Z, Bobaru F (2015) Peridynamic modeling of pitting corrosion damage. J Mech Phys Solids 78:352-381

62. Wang Y-T, Zhou X-P (2019) Peridynamic simulation of thermal failure behaviors in rocks subjected to heating from boreholes. Int J Rock Mech Mining Sci 117:31-48

63. Shojaei A, Hermann A, Seleson P, Cyron C (2020) Dirichlet absorbing boundary conditions for classical and peridynamic diffusion-type models. Comput Mech 66:773-793

64. Bazazzadeh S, Shojaei A, Zaccariotto M, Galvanetto U (2019) Application of the peridynamic differential operator to the solution of sloshing problems in tanks. Eng Comput (Swansea, Wales) 36(1):45-83

65. Song Y, Liu R, Li S, Kang Z, Zhang F (2019) Peridynamic modeling and simulation of coupled thermomechanical removal of ice from frozen structures. Meccanica 55:1-16

66. Ballarini R, Diana V, Biolzi L, Casolo S (2018) Bond-based peridynamic modelling of singular and nonsingular cracktip fields. Meccanica 53(14):3495-3515

67. Madenci E, Oterkus E (2014) Peridynamic theory. Springer, pp 19-43

68. Bobaru F, Foster JT, Geubelle PH, Silling SA (2016) Handbook of peridynamic modeling. CRC Press

69. Chen Z, Bobaru F (2015) Selecting the kernel in a peridynamic formulation: a study for transient heat diffusion. Comput Phys Commun 197:51-60

70. Silling S, Bobaru F (2005) Peridynamic modeling of membranes and fibers. Int $\mathrm{J}$ Non-Linear Mech 40(2):395-409 special Issue in Honour of C.O. Horgan

71. Lackner R, Mang HA (2004) Chemoplastic material model for the simulation of early-age cracking: from the constitutive law to numerical analyses of massive concrete structures. Cement Concrete Compos 26(5):551-562

72. Emmrich E, Weckner O (2007) The peridynamic equation and its spatial discretisation. Math Model Anal 12(1):17-27

73. Yu K, Xin XJ, Lease KB (2011) A new adaptive integration method for the peridynamic theory. Model Simul Mater Sci Eng 19(4):045003

74. Stefan L, Benboudjema F, Torrenti J-M, Bissonnette B (2010) Prediction of elastic properties of cement pastes at early ages. Comput Mater Sci 47(3):775-784

75. Rossi Cabral N, Invaldi MA, Barrios D’Ambra R, Iturrioz I (2019) An alternative bilinear peridynamic model to simulate the damage process in quasi-brittle materials. Eng Fract Mech 216:106494

76. Niazi S, Chen Z, Bobaru F (2021) Crack nucleation in brittle and quasi-brittle materials: a peridynamic analysis. Theor Appl Fracture Mechanics 112:102855

77. Tong Y, Shen W, Shao J, Chen J (2020) A new bond model in peridynamics theory for progressive failure in cohesive brittle materials. Eng Fract Mech 223:106767

78. Yang D, Dong W, Liu X, Yi S, He X (2018) Investigation on mode-I crack propagation in concrete using bond-based peridynamics with a new damage model. Eng Fract Mech 199:567-581 
79. Chen Z, Niazi S, Bobaru F (2019) A peridynamic model for brittle damage and fracture in porous materials. Int J Rock Mech Mining Sci 122:104059

80. Day AS (1965) An introduction to dynamic relaxation. Engineer 4:218-221

81. Kilic B, Madenci E (2010) An adaptive dynamic relaxation method for quasi-static simulations using the peridynamic theory. Theor Appl Fract Mech 53(3):194-204

82. Huang D, Lu G, Qiao P (2015) An improved peridynamic approach for quasi-static elastic deformation and brittle fracture analysis. Int J Mech Sci 94-95:111-122
83. Weiler M investigation of crack development in a fair faced replacement screed based on hybrid reinforced concrete. PhD thesis, University of Luxembourg

84. Azenha M (2004) Behaviour of concrete at early ages. phenomenology and thermo-mechanical analysis. MSc thesis, Faculty of Engineering of the University of Porto

Publisher's Note Springer Nature remains neutral with regard to jurisdictional claims in published maps and institutional affiliations. 